In the format provided by the authors and unedited.

\title{
Global-scale hydrological response to future glacier mass loss
}

Matthias Huss ${ }^{1,2 \star}$ and Regine Hock $^{3,4}$

'Laboratory of Hydraulics, Hydrology and Glaciology (VAW), ETH Zurich, Zurich, Switzerland. 'Department of Geosciences, University of Fribourg, Fribourg, Switzerland. ${ }^{3}$ Geophysical Institute, University of Alaska Fairbanks, Fairbanks, AK, USA. ${ }^{4}$ Department of Earth Sciences, Uppsala University, Uppsala, Sweden. *e-mail: huss@vaw.baug.ethz.ch 


\section{TABLE OF CONTENT:}

\section{Supplementary Text}

- The concept of "peak water" (Page 2)

\section{Supplementary Figures}

- Figure S1: Map of glacier runoff increase until peak water. (Page 3)

- Figure S2: Timing of peak water versus different variables. (Page 4)

- Figure S3: 21 st century changes in glacier runoff seasonality for all 56 investigated basins. (Page 5-8)

- Figure S4: Future changes in glacier runoff versus glacier area loss. (Page 9)

- Figure S5: Map of glacier runoff changes in July and August between 2000 and 2090. (Page 10)

- Figure S6: Map of glacier runoff changes in September and October between 2000 and 2090. (Page 11)

- Figure S7: Projected monthly glacier runoff changes relative to basin runoff for all 56 basins. (Page 12)

- Figure S8: Overview of results for all 56 investigated basins in September (March in the southern hemisphere). (Page 13)

- Figure S9: Long-term runoff observations. (Page 14)

\section{Supplementary Tables}

- Table S1: Characteristics of all 56 investigated glacierized drainage basins. (Page 15)

- Table S2: Global Circulation Models from the CMIP5 project used in this study. (Page 16)

- Table S3: Modelled timing of peak water with uncertainties for all investigated basins. (Page 17)

- Table S4: Projected monthly glacier runoff changes, $\Delta Q_{\mathrm{g}}$, including uncertainties. (Page 18)

- Table S5: Projected glacier runoff changes relative to basin runoff, $\Delta Q_{\mathrm{g}}^{\prime} / Q_{\text {basin }}$, including uncertainties. (Page 19)

- Table S6: Observed long-term average monthly runoff for June to September for the investigated basins. (Page 20) 


\section{SUPPLEMENTARY TEXT}

\subsection{The concept of "peak water"}

The concept of peak water (Fig. 1, main text) refers to the variation of glacier runoff with time as the climate warms and glaciers retreat. Annual runoff will initially increase, but then peak, followed by a decline. Peak water refers to the timing of peak flow, which is a critical variable for water resources planning and management in catchments in which glacier runoff is a significant contributor to streamflow.

Initially $\left(t_{0}-t_{1}\right)$, the glacier is in balance, i.e. averaged over the entire glacier and one year, seasonal glacier volume losses (mostly melt) are compensated by accumulation of snow, thus annual glacier mass change $\Delta M_{\mathrm{a}}=0$. Assuming other water balance components to be negligible, the annual runoff is given by $Q_{\mathrm{a}}=P_{\mathrm{a}}-E_{\mathrm{a}}$, where $P_{\mathrm{a}}$ is annual precipitation and $E_{\mathrm{a}}$ evaporation.

When $\Delta M$ turns negative in response to atmospheric warming $\left(t_{1}\right)$, the annual runoff from the glacierized basin will first increase due to enhanced melt. A tipping point is reached beyond which the annual runoff will decrease, since the additional water provided by annual glacier storage change decreases as the glacier mass shrinks. During this phase $\left(t_{1}\right.$ $\left.t_{2}\right), Q_{\mathrm{a}}=P_{\mathrm{a}}-E_{\mathrm{a}}-\Delta M_{\mathrm{a}}$. Assuming that all components of the water balance over the glacierized basin (precipitation, evapotranspiration, groundwater storage, human water extraction, etc.), except for glacier storage change, $\Delta M_{\mathrm{a}}$, remain unaltered, the runoff will return to its initial value at $t_{1}$ once the glacier has disappeared or reached a new equilibrium (i.e. $\Delta M_{\mathrm{a}}=0$, and $Q_{\mathrm{a}}=P_{\mathrm{a}}-E_{\mathrm{a}}$ ). Hence, the basin runoff is identical at $t_{1}$ and $t_{2}$, although glacier coverage is different. As long as $\Delta M_{\mathrm{a}}=0$ (i.e. the glacier is not gaining or losing mass over the course of a year), there is no additional runoff component due to changes in glacier storage no matter glacier size, or whether or not the basin is glacierized at all. Note that the runoff volume derived from integrating annual runoff in excess of the initial value at $t_{1}$ is equal to the total glacier volume lost in period $t_{1}-t_{2}$, or equal to total initial glacier volume in case the glacier has melted entirely.

Here, summer runoff is defined as the runoff over each year's melt season which varies in length in different climates. It will experience similar changes as annual runoff, but will eventually drop below its initial value at $t_{1}$, since summer glacier mass balances are typically strongly negative (net mass losses), and therefore summer runoff $Q_{\mathrm{s}}=P_{\mathrm{s}}-E_{\mathrm{s}}-\Delta M_{\mathrm{s}}$. Hence, as long as the glacier exists, during summer, additional water is provided from glacier storage (even in years with balanced or positive mass budgets, i.e. when $\Delta M_{\mathrm{a}} \geq 0$ ). However, this excess water from the glacier will eventually drop below its initial value at $t_{1}$ as the glacier continues to shrink. The fraction of runoff in the remaining months of the year increases relative to annual runoff as more precipitation falls as rain and the glacier influence is diminished.

The changes in summer runoff illustrated in Figure 1 of the main text refer to glaciers in climates with a pronounced melt and accumulation season as typically found in mid- and high-latitudes, while glaciers in the tropics or monsoon-dominated regions may show different regimes. In reality, runoff evolution may substantially deviate from this schematic concept since other components of the water balance (e.g. precipitation, evapotranspiration) are expected to change in response to both the air temperature changes and land cover (e.g. vegetation) and morphological changes (e.g. proglacial lake formation) that may occur when glaciers retreat.

Similar illustrations have been reported in the literature ${ }^{1-4}$. In contrast to Figure 1 (main text), Milner et al. ${ }^{2}$ and Baraer et al. ${ }^{4}$ show a decrease in annual runoff below the initial value as the glacier disappears but refer to runoff from the continuously changing glacierized area. Here, we isolate the glacier impact on runoff from a highly glacierized basin, fixed in area, including glacierized and increasingly non-glacierized terrain. 


\section{SUPPLEMENTARY FIGURES}

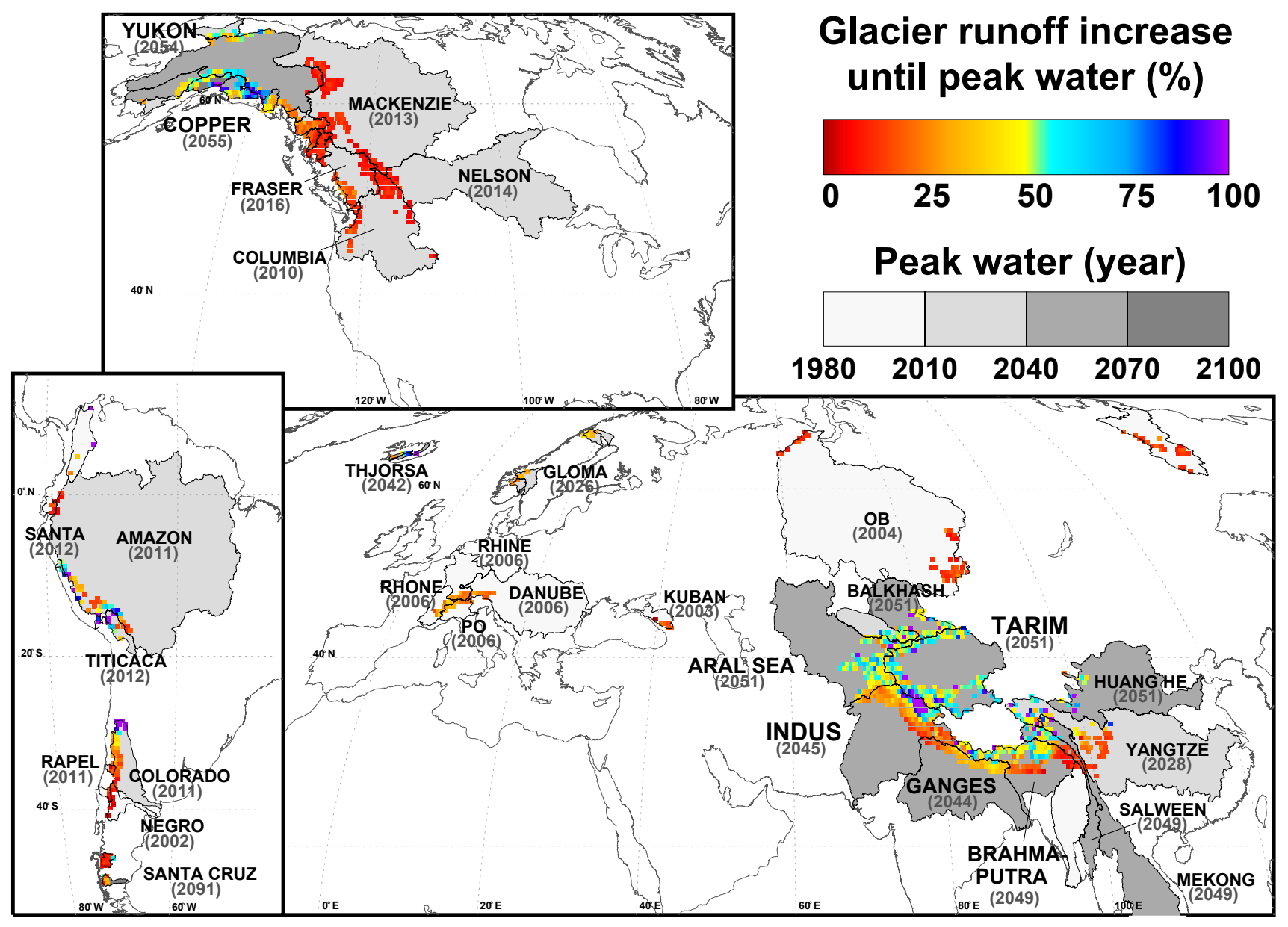

Supplementary Figure 1. Increase in annual glacier runoff until peak water relative to $1980-2000(\%)$. Colours show the runoff increase for all glaciers located in the 56 investigated drainage basins, aggregated in $0.5 \times 0.5^{\circ}$ grid cells. Grey scales refer the year of peak water for the macroscale basins in 30-year intervals. Peak water (in years) is also given in brackets below the basin names. Glacier runoff is defined as runoff from the initially glacierized area. Peak water is computed from 11-year moving averages of annual glacier runoff. Results refer to multi-GCM means and RCP4.5. 

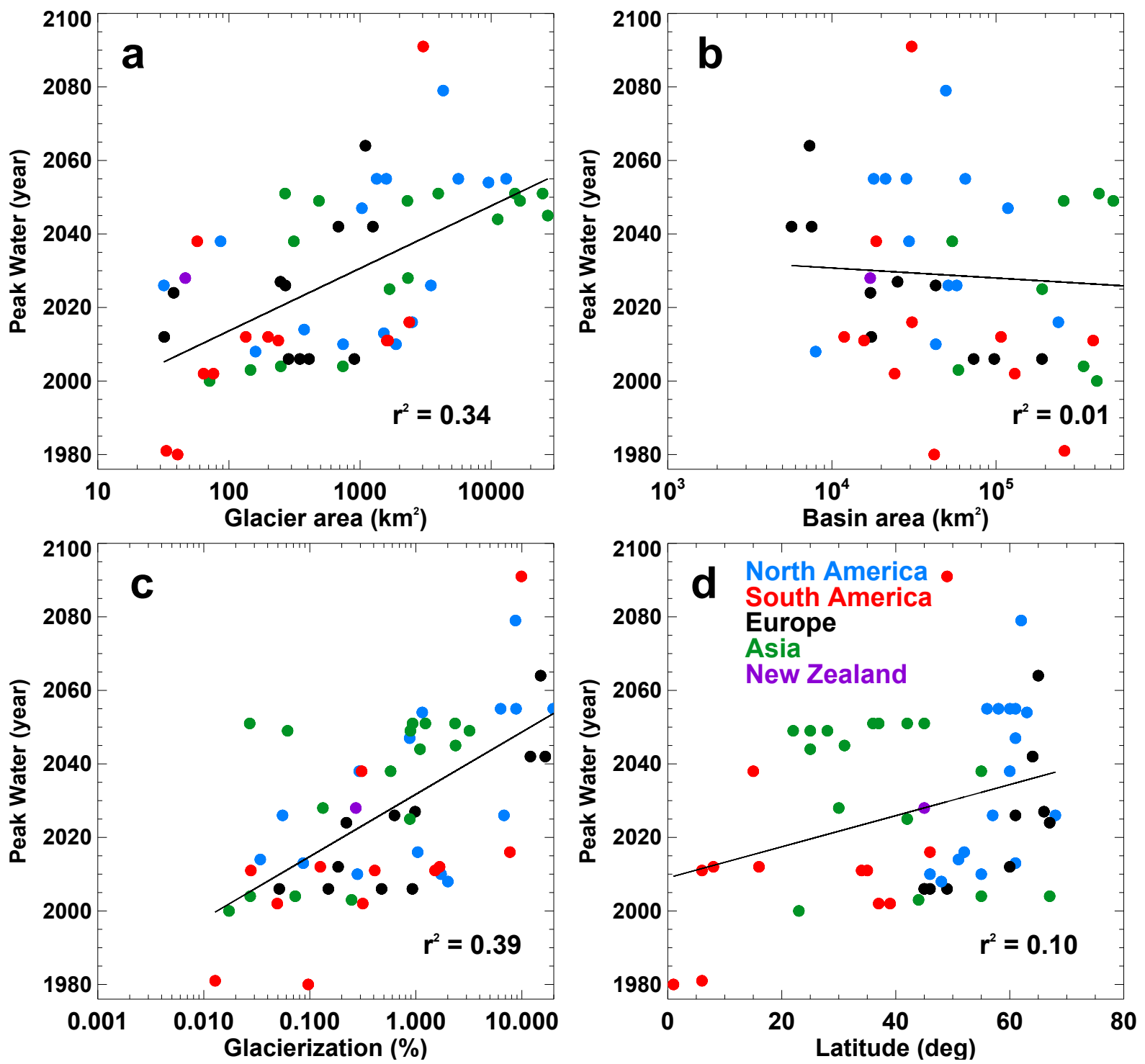

Supplementary Figure 2. Timing of peak water in all 56 investigated glacierized macroscale drainage basins in dependence of different variables. a, Total glacier area in the drainage basin, $\mathbf{b}$, basin area, $\mathbf{c}$, glacierization, and $\mathbf{d}$, absolute geographic latitude of the basin's center. Symbols are colour-coded to continents and refer to multi-GCM means and emission scenario RCP4.5. Coefficients of determination $\left(r^{2}\right)$ in a-c are given for a logarithmic representation of the dependent variable. All correlations, except for basin area (b) are significant at the $\mathrm{p}<0.01$ level. 
INDUS

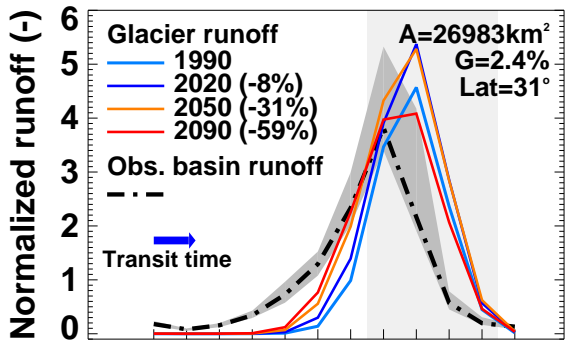

Jan. Mar. May Jul. Sep. Nov.

ARAL SEA

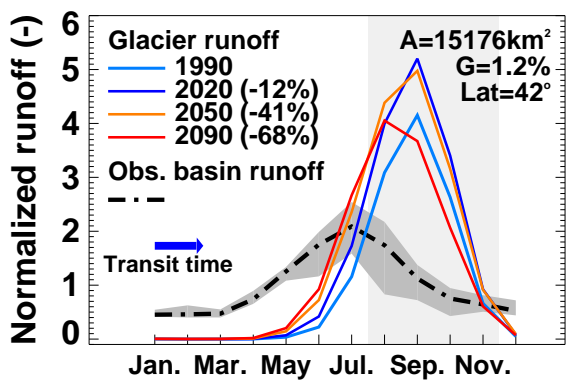

YUKON

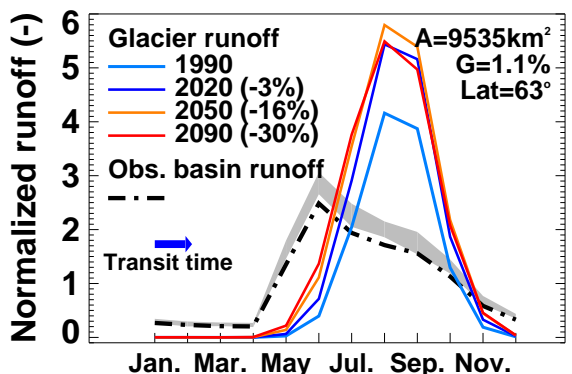

BALKHASH

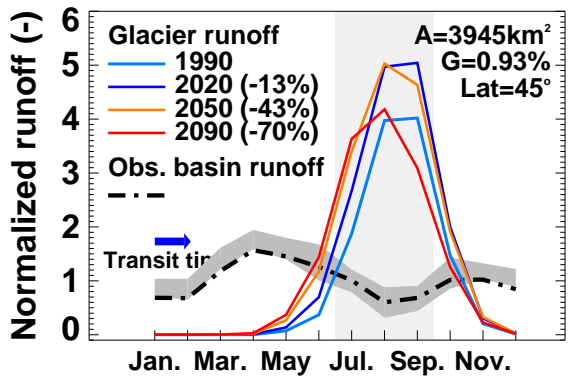

TARIM

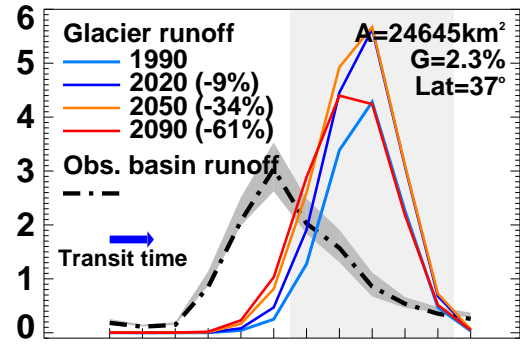

Jan. Mar. May Jul. Sep. Nov.

COPPER

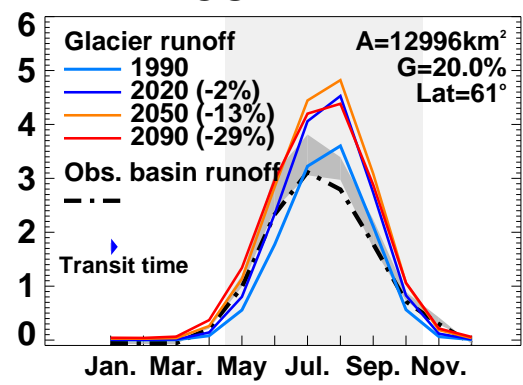

ALSEK

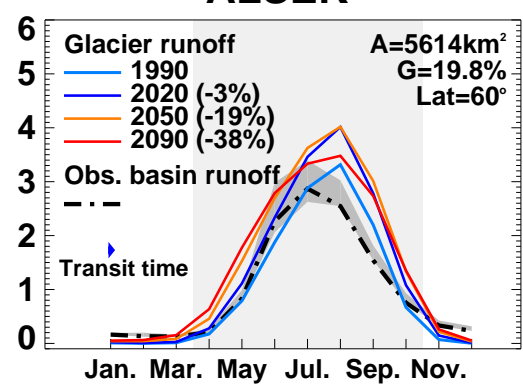

STIKINE

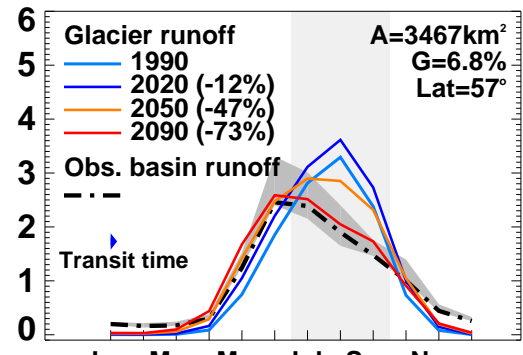

Jan. Mar. May Jul. Sep. Nov.
BRAHMAPUTRA

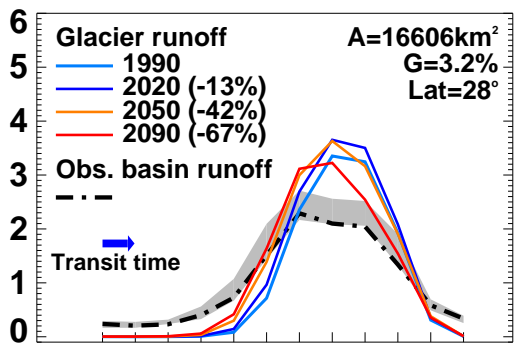

Jan. Mar. May Jul. Sep. Nov.

\section{GANGES}

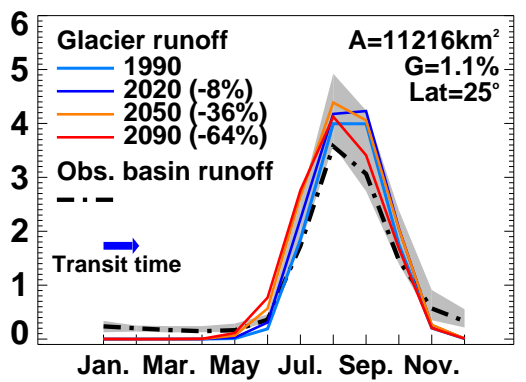

SUSITNA

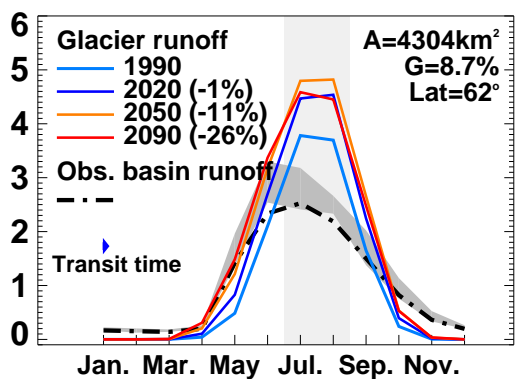

SANTA CRUZ

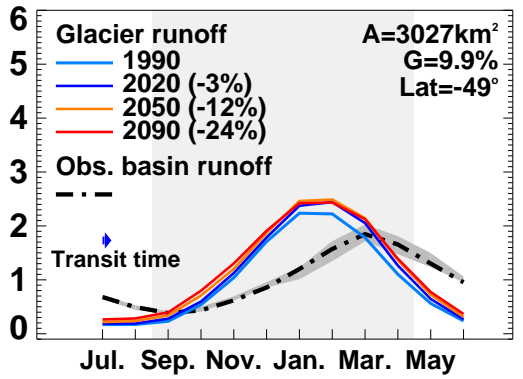

Supplementary Figure 3. $\quad \mathbf{2 1}^{\text {st }}$ century changes in glacier runoff seasonality for individual glacier basins (continued on next three pages). Modelled monthly mean glacier runoff (shifted by water transit time) is averaged over four 20-year periods (1980-2000, 2010-2030, 2040-2060, 2080-2100) and normalized with respect to each basin's mean annual runoff in 1980-2000. Results refer to the multi-GCM mean and RCP4.5. Also shown is observed monthly mean basin runoff 5,6 normalized with mean annual runoff over basin-specific periods of available data (see Suppl. Table 6). The area in dark grey indicates the spread in basin runoff by the end of the $21^{\text {st }}$ century when basin runoff is adjusted based on precipitation changes from $14 \mathrm{GCMs}$, as done in our sensitivity experiment (see Methods). Present glacier area, $A$, glacierization, $G$, and geographic latitude, Lat., of the basin's center are given. Numbers in brackets refer to the modelled change in glacier area for 2020, 2050 and 2090 relative to initial ice coverage (referring to the period between 2000 and 2010). Grey bars mark the months with shares of modelled glacier runoff (1980-2000) relative to observed basin runoff of $>30 \%$. The length of the blue arrows is linearly proportional to each basin's transit time (see Supp. Table 1). The basins are shown in the order of decreasing glacier area. 
FRASER

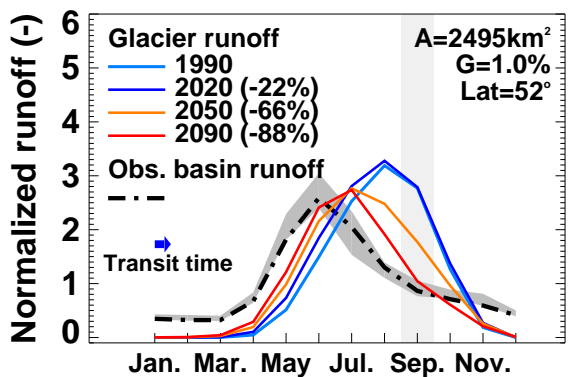

SALWEEN

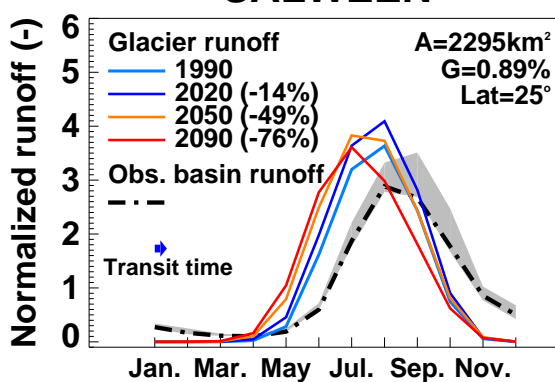

AMAZON

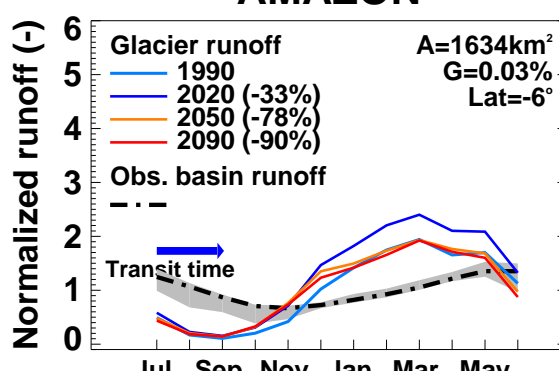

Jul. Sep. Nov. Jan. Mar. May

MACKENZIE

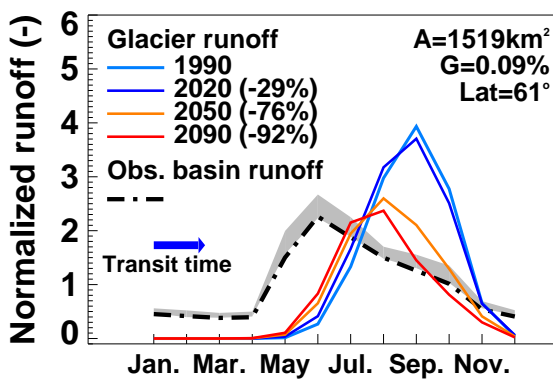

JOEKULSA A F.

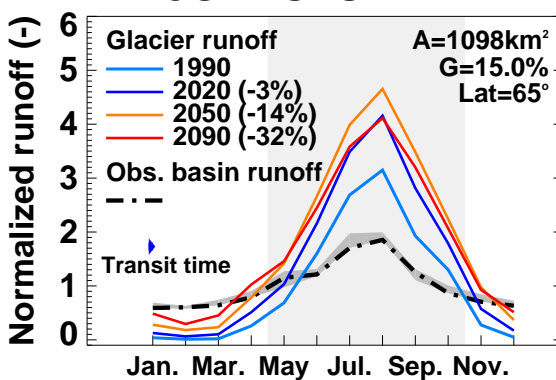

Jan. Mar. May Jul. Sep. Nov.
BAKER

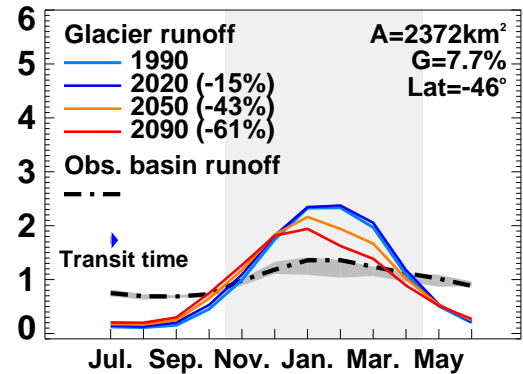

COLUMBIA

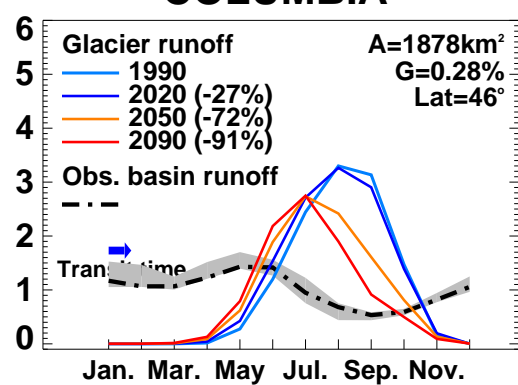

COLORADO

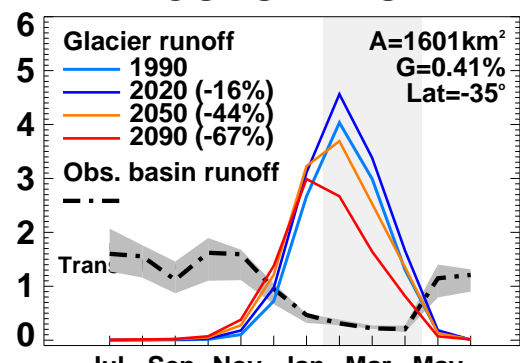

Jul. Sep. Nov. Jan. Mar. May

NASS

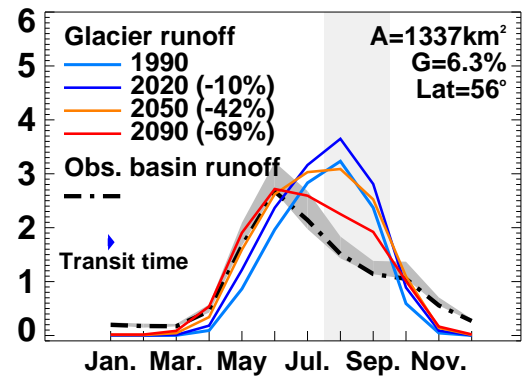

KUSKOKWIM

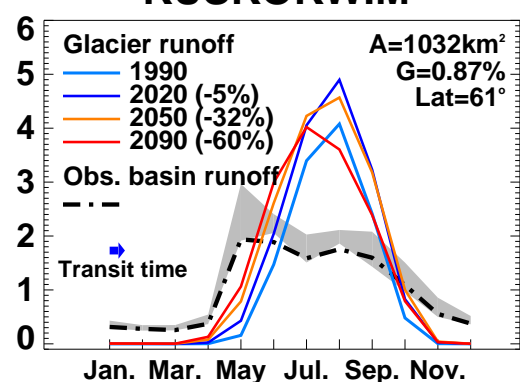

YANGTZE

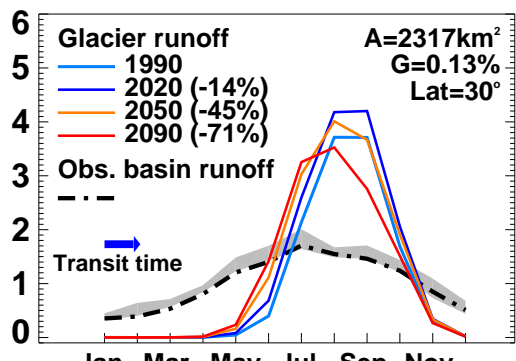

Jan. Mar. May Jul. Sep. Nov.

ISSYK-KUL

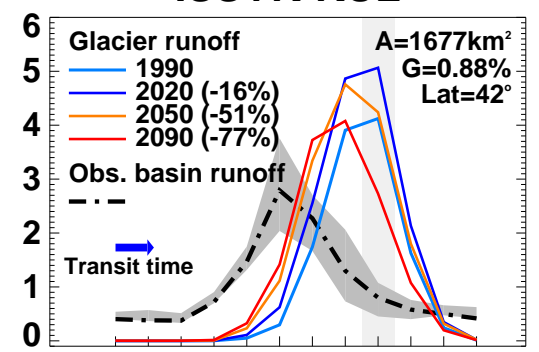

Jan. Mar. May Jul. Sep. Nov.

\section{TAKU}

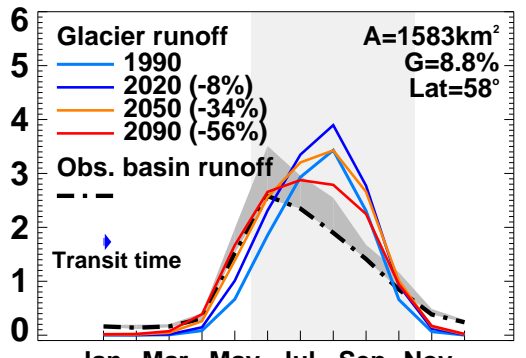

Jan. Mar. May Jul. Sep. Nov.

\section{THJORSA}

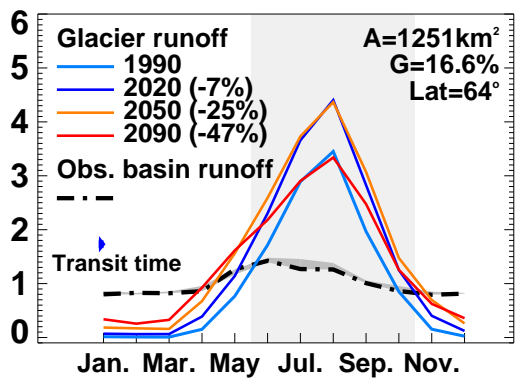

RHONE

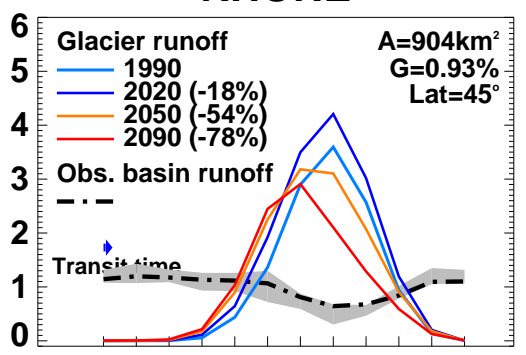

Jan. Mar. May Jul. Sep. Nov. 
SKEENA

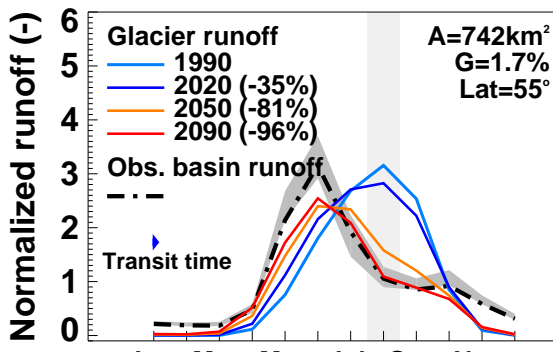

Jan. Mar. May Jul. Sep. Nov.

MEKONG

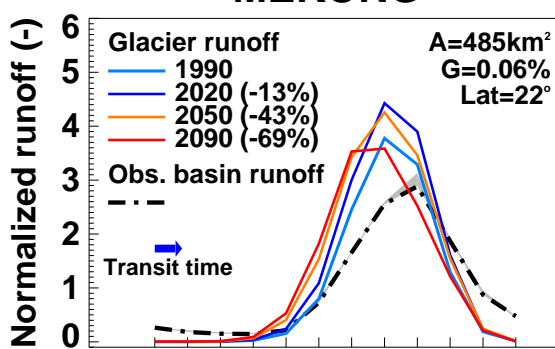

Jan. Mar. May Jul. Sep. Nov.

\section{PO}

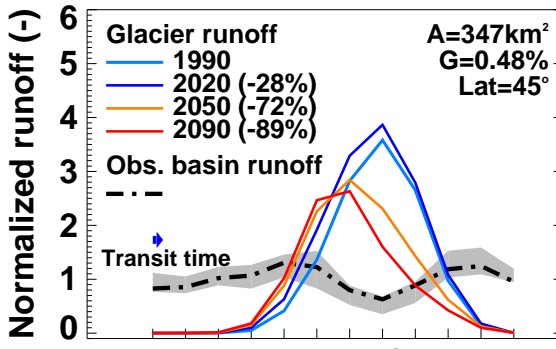

Jan. Mar. May Jul. Sep. Nov.

\section{GLOMA}

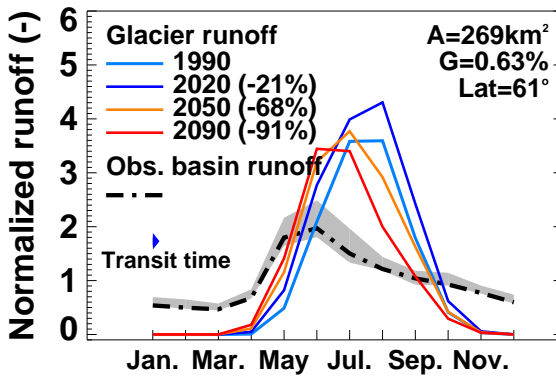

\section{LULE}

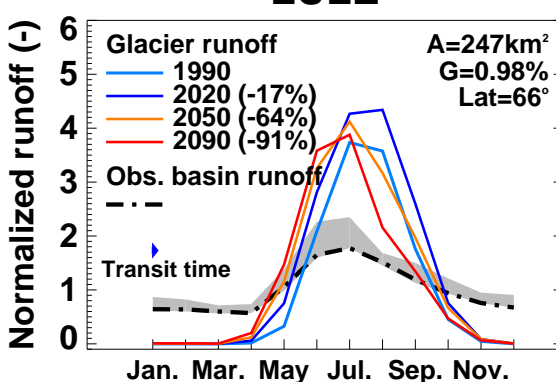

Jan. Mar. May Jul. Sep. Nov.
OB

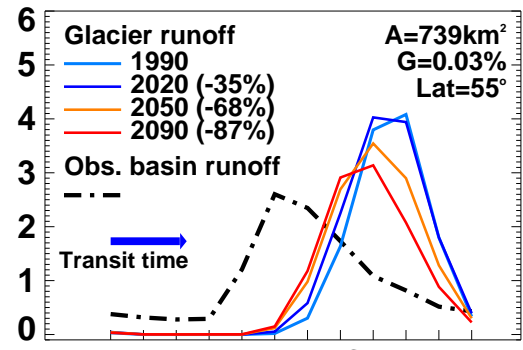

Jan. Mar. May Jul. Sep. Nov.

DANUBE

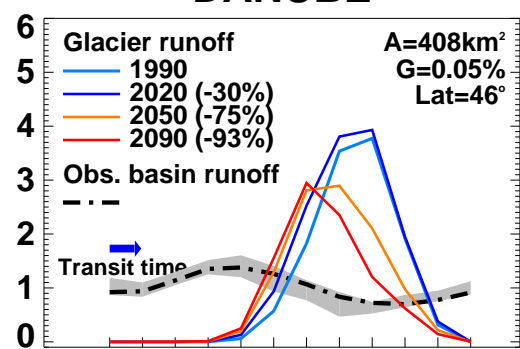

Jan. Mar. May Jul. Sep. Nov.

KAMCHATKA

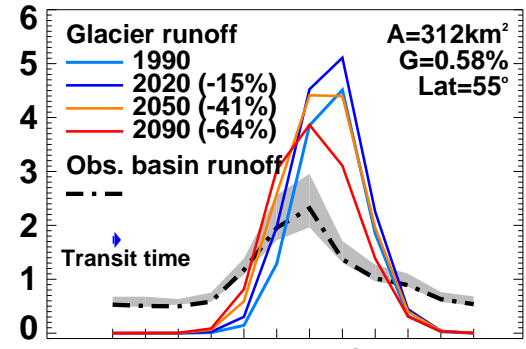

Jan. Mar. May Jul. Sep. Nov.

HUANG HE

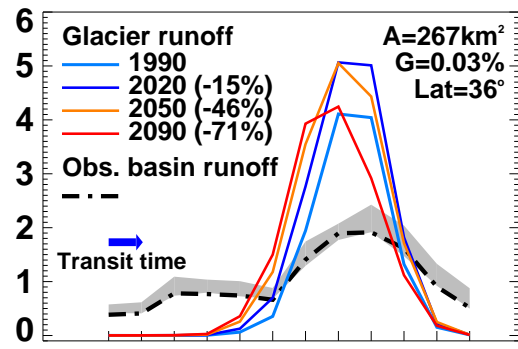

Jan. Mar. May Jul. Sep. Nov.

\section{RAPEL}

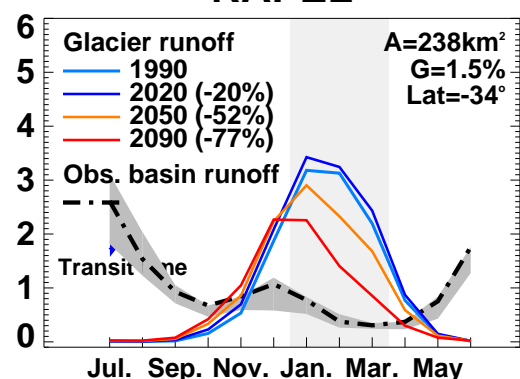

OELFUSA

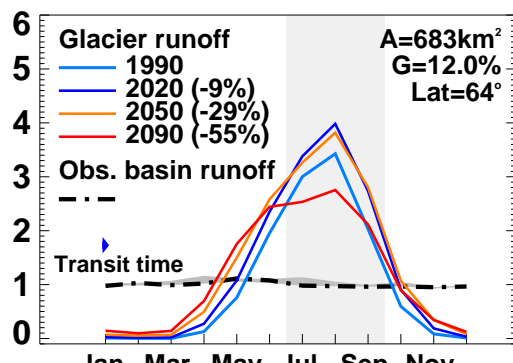

Jan. Mar. May Jul. Sep. Nov.

NELSON

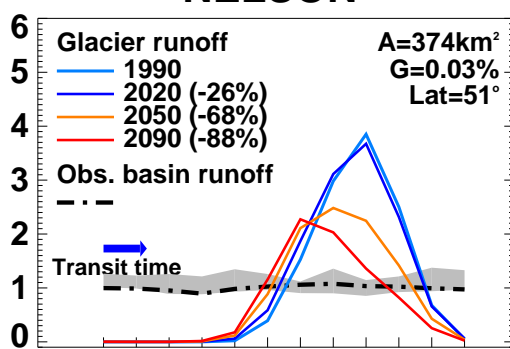
Jan. Mar. May Jul. Sep. Nov.

\section{RHINE}

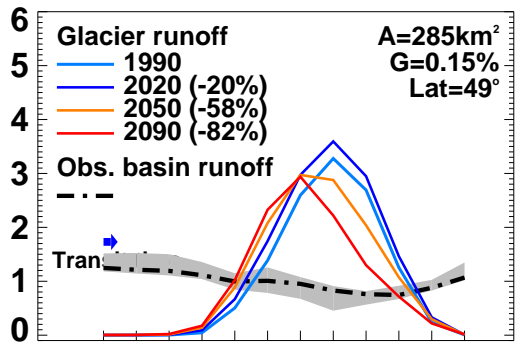

Jan. Mar. May Jul. Sep. Nov.

\section{INDIGIRKA}

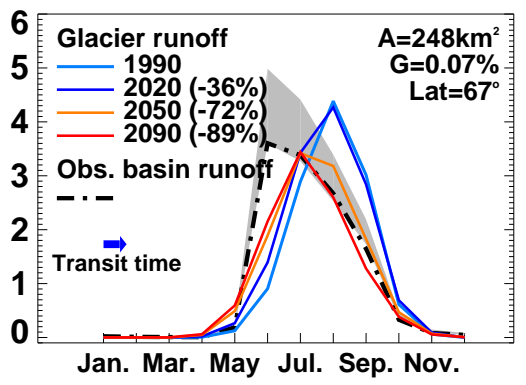

SANTA

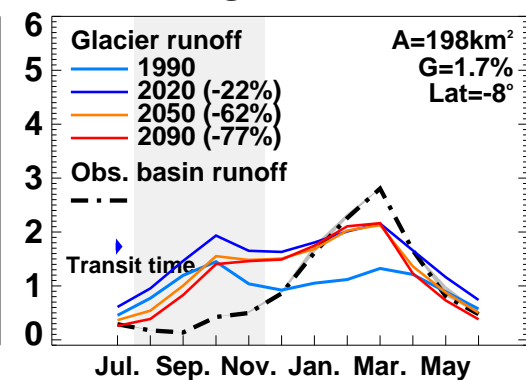


SKAGIT

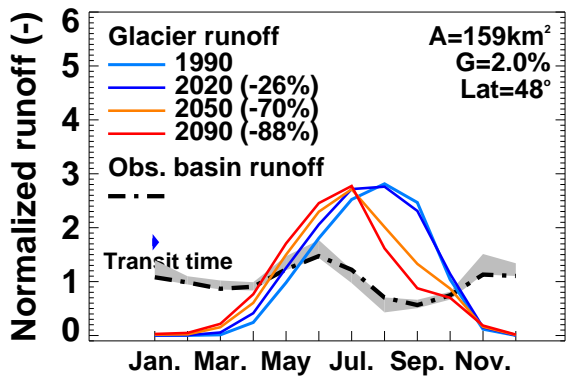

NUSHAGAK

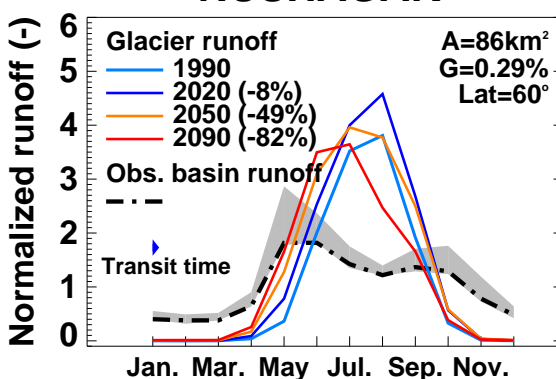

NEGRO

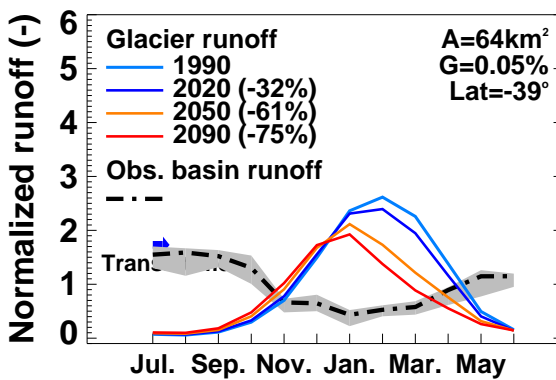

DAULE/VINCES

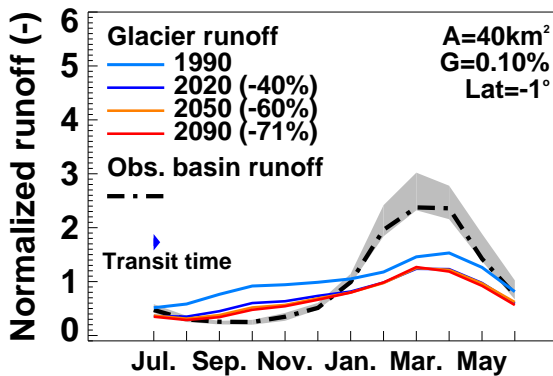

DRAMSELV

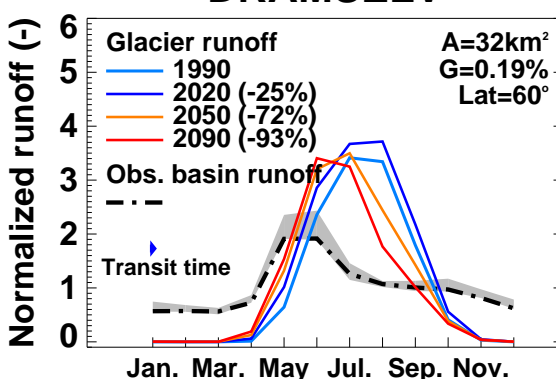

Jan. Mar. May Jul. Sep. Nov.
KUBAN

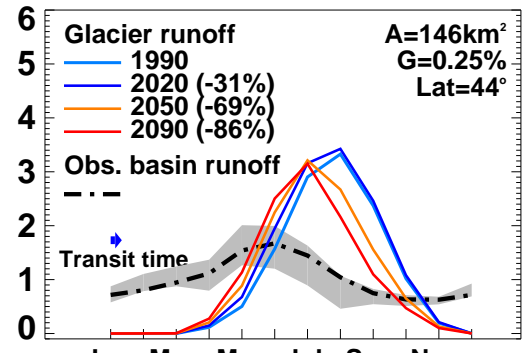

Jan. Mar. May Jul. Sep. Nov.

\section{BIOBIO}

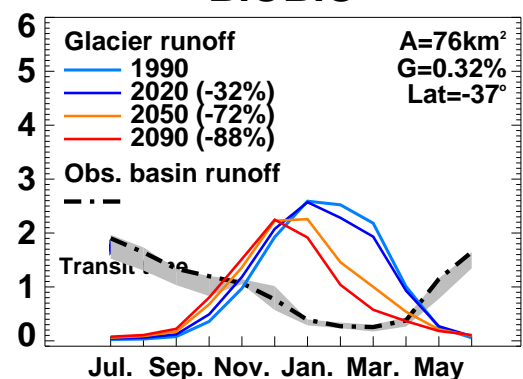

MAJES

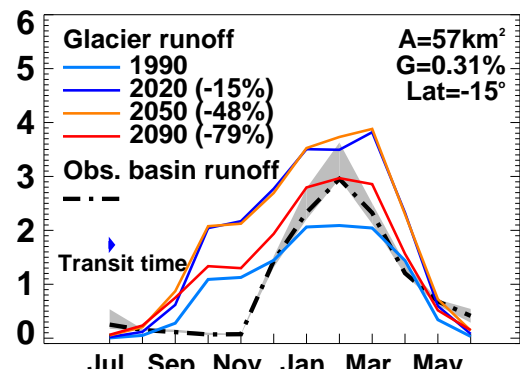

KALIXAELVEN

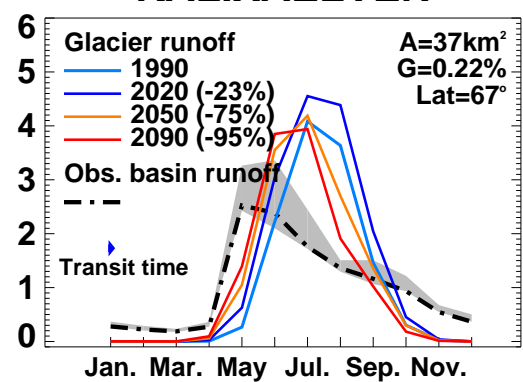

COLVILLE

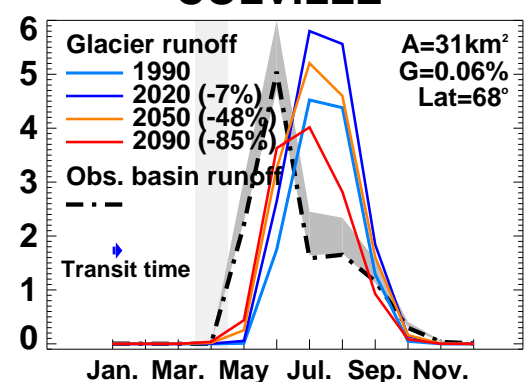

TITICACA

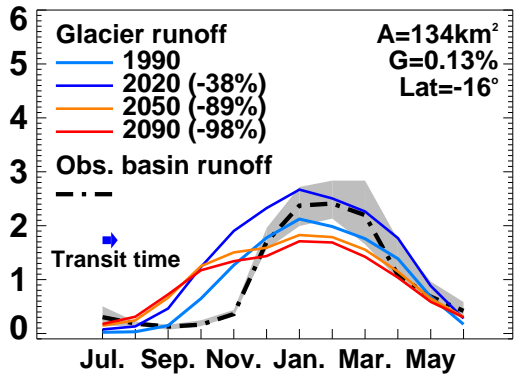

IRRAWADDY

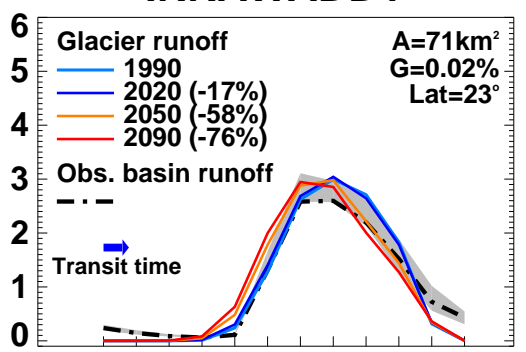

Jan. Mar. May Jul. Sep. Nov.

\section{CLUTHA}

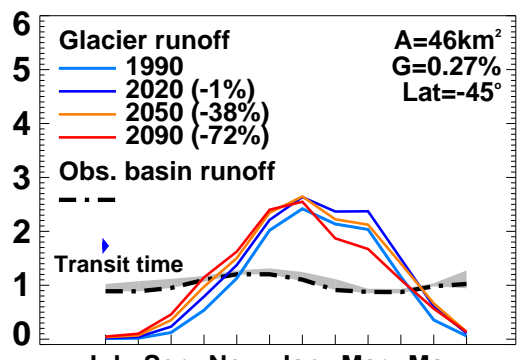

Jul. Sep. Nov. Jan. Mar. May

MAGDALENA

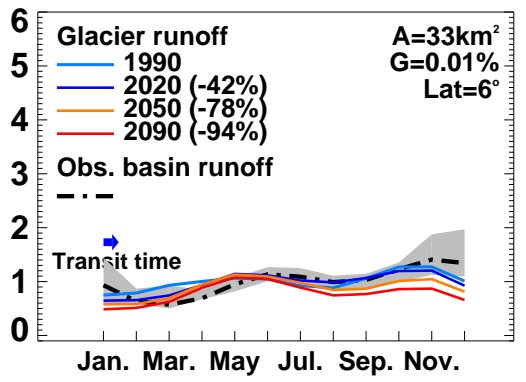



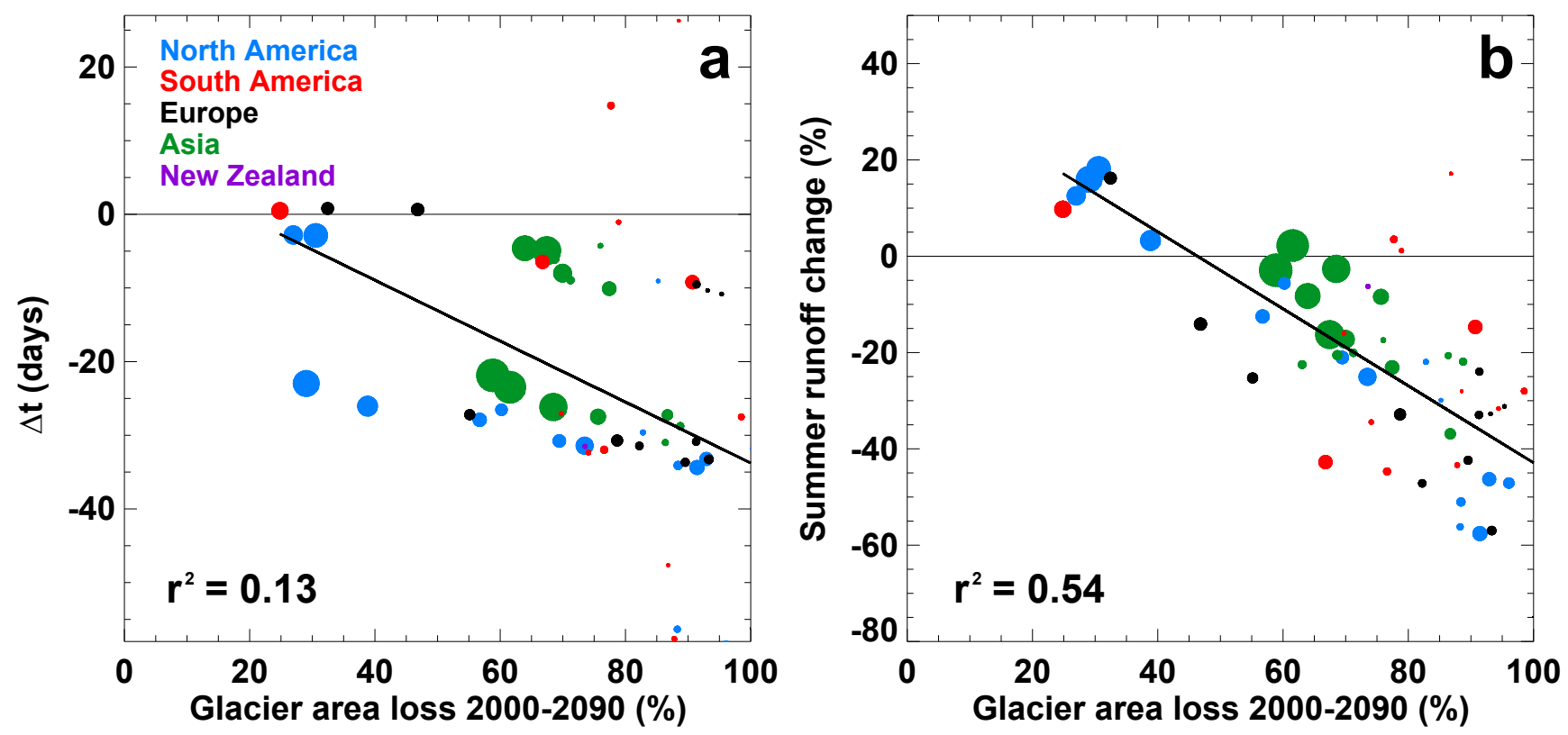

Supplementary Figure 4. Dependence of future changes in glacier runoff of all 56 investigated basins with glacier area loss over the period 2000 to 2090. Changes are computed from 20 -year averages centered around these years. a, Change in the timing when the modelled seasonal maximum glacier runoff occurs in a year, $\Delta t$, versus glacier area loss. Negative values of $\Delta t$ indicate that the runoff maximum occurs earlier in the season. To achieve finer than monthly resolution, $\Delta t$ was computed from the shift of the center of gravity of the three months with the highest runoff volumes. The grouping of the basins into two distinct clusters separated by about 20 days results from the monthly model resolution. b. Change in summer glacier runoff versus glacier area loss over the same 90-year period. The runoff change is computed from the runoff volume of each year's two consecutive months with maximum runoff. Results refer to multi-GCM means and RCP4.5. Circle area scales linearly with the basin's glacier area, and colours indicate basin location. With decreasing glacier area, the seasonal discharge maximum occurs earlier in the year ( 0.4 days per percent glacier area loss), and summer runoff decreases $(0.8 \%$ per percent glacier area loss). Note that for glacier area changes of less than about $-40 \%$, higher summer runoff is projected. $r^{2}$ is the coefficient of determination. The correlations are statistically significant at the $p<0.01$ level according to the F-test. 

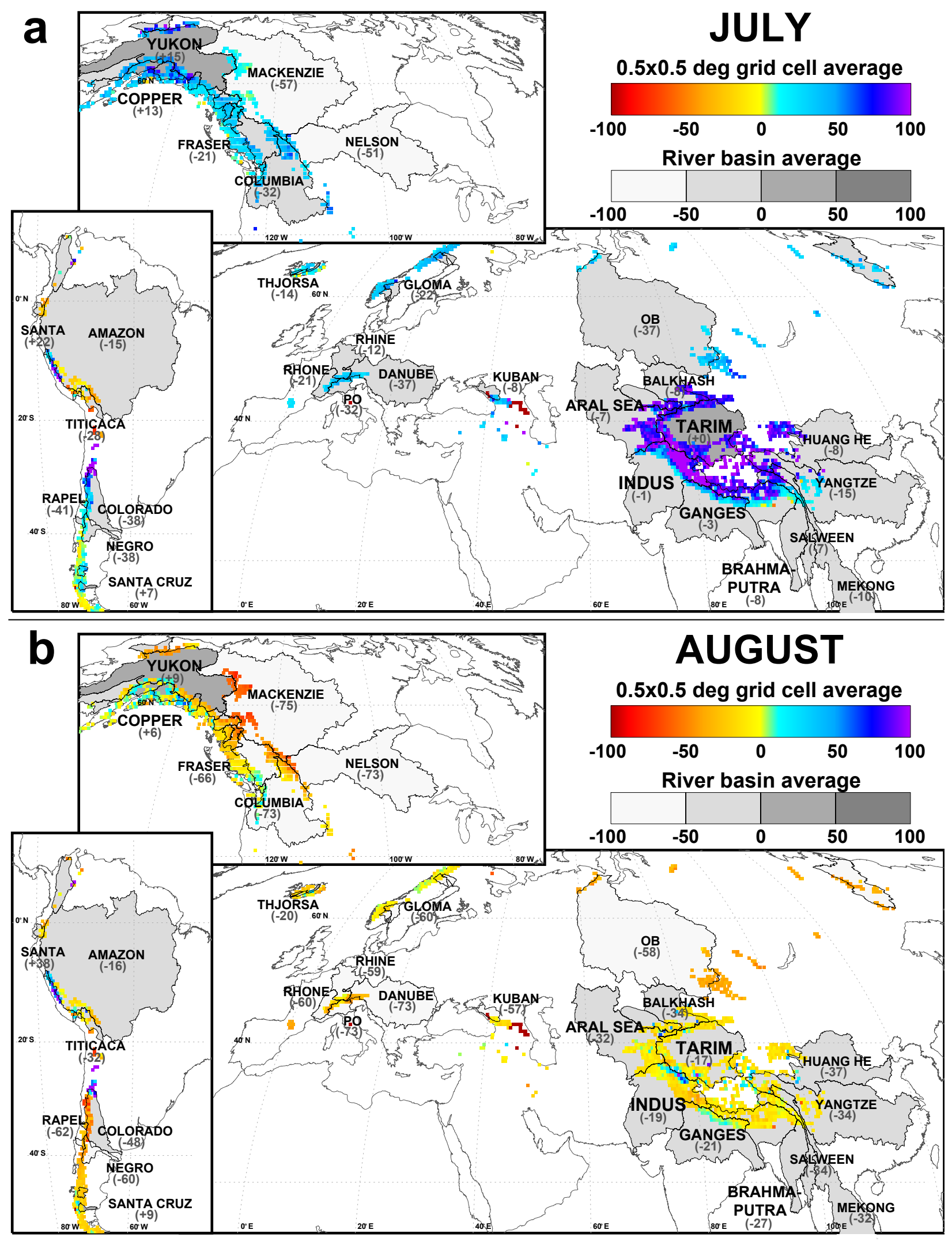

Supplementary Figure 5. Glacier runoff changes in (a) July and (b) August between 2000 and 2090. (January/February for southern hemisphere) Changes are computed from 20-year averages centered around these years and based on the glacier runoff volume from all glaciers for (i) each glacierized $0.5 \times 0.5^{\circ}$ grid cell (colour scale, including cells outside the investigated basins), and (ii) each investigated river basin (grey-scale). Glacier runoff is defined as runoff from the initially glacierized area. Results refer to multi-GCM means and RCP4.5. 

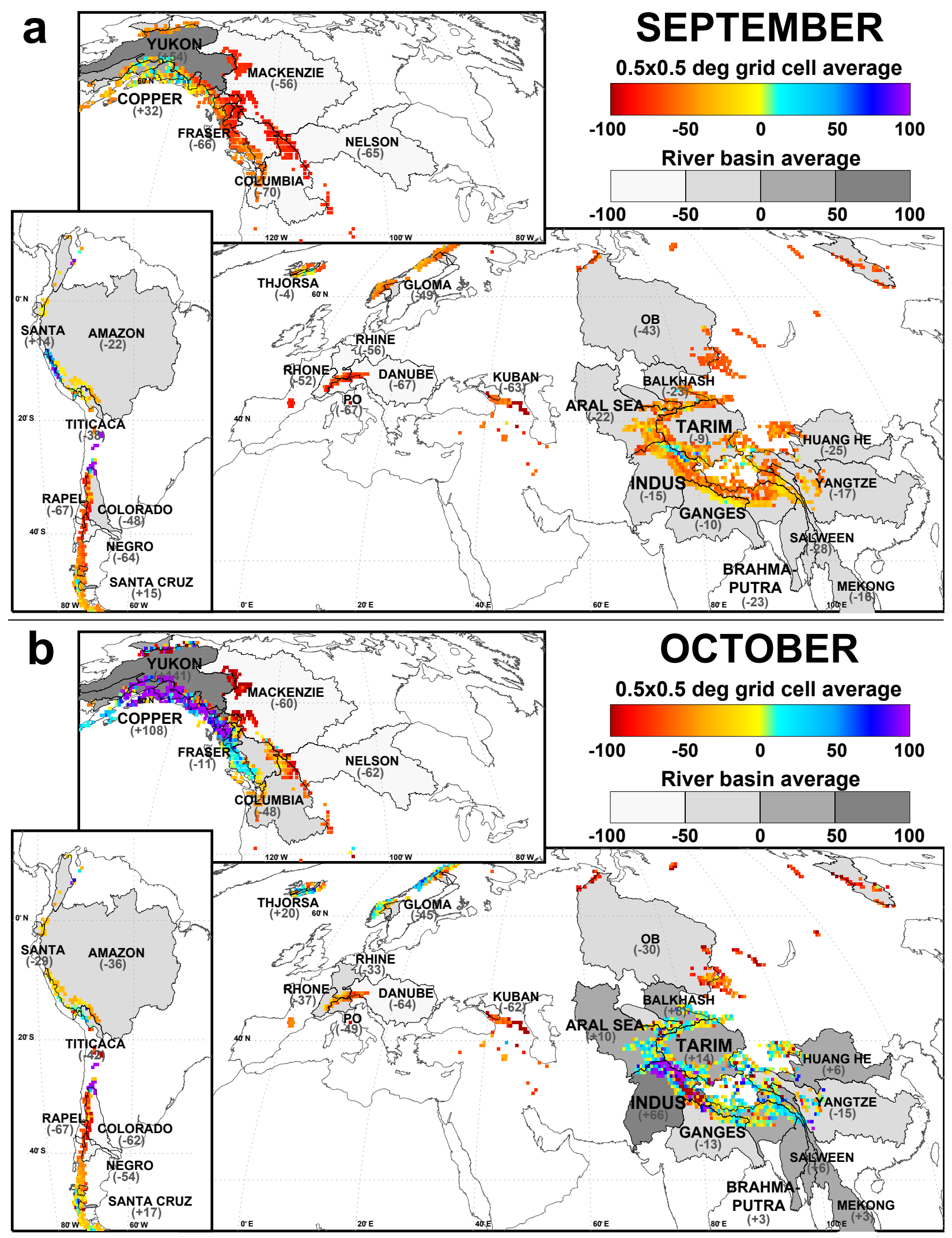

Supplementary Figure 6. Glacier runoff changes in (a) September and (b) October between 2000 and 2090 (March/April for southern hemisphere). Changes are computed from 20-year averages centered around these years and based on the glacier runoff volume from all glaciers for (i) each glacierized $0.5 \times 0.5^{\circ}$ grid cell (colour scale, including cells outside the investigated basins), and (ii) each investigated river basin (grey-scale). Glacier runoff is defined as runoff from the initially glacierized area. Results refer to multi-GCM means and RCP4.5. 


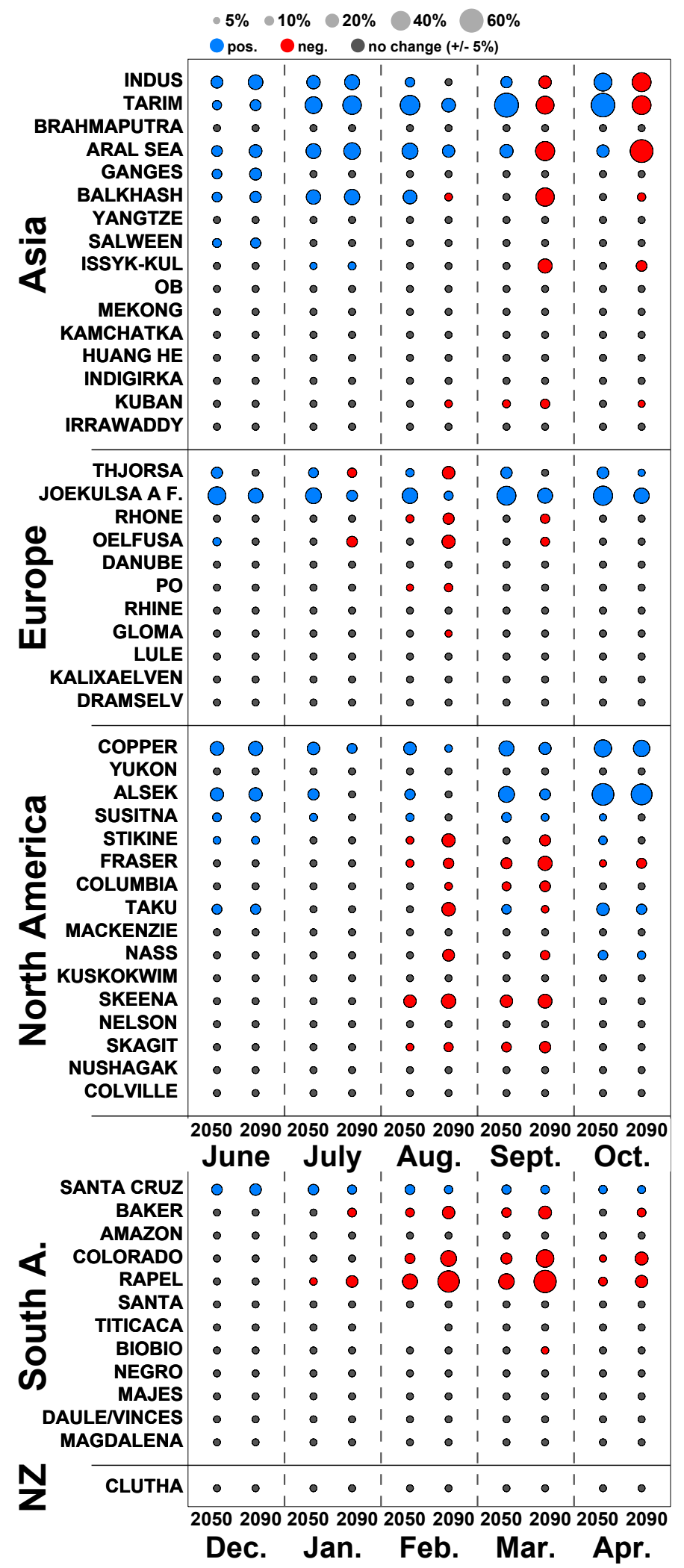

Supplementary Figure 7. Projected glacier runoff changes relative to basin runoff, $\Delta Q_{\mathrm{g}}^{\prime} / Q_{\text {basin }}$. Monthly glacier runoff changes, $\Delta Q_{\mathrm{g}}^{\prime}$, refer to the periods 2000 to 2050, and 2000 to 2090, and are computed from 20-year averages centered around these years. Glacier runoff is defined as runoff from the initially glacierized area and is shifted to account for water transit times to the drainage basin's mouth (see Methods). $\Delta Q_{\mathrm{g}}^{\prime} / Q_{\text {basin }}$ is evaluated for the months June to October (December to April for southern hemisphere). The area of the dots scales linearly with the absolute values of $\Delta Q_{\mathrm{g}}^{\prime} / Q_{\text {basin }}$ using the same scale as in Figure 3 of the main text. Results refer to multi-GCM means and RCP4.5. Basins are listed for each continent in the order of decreasing glacier area. 


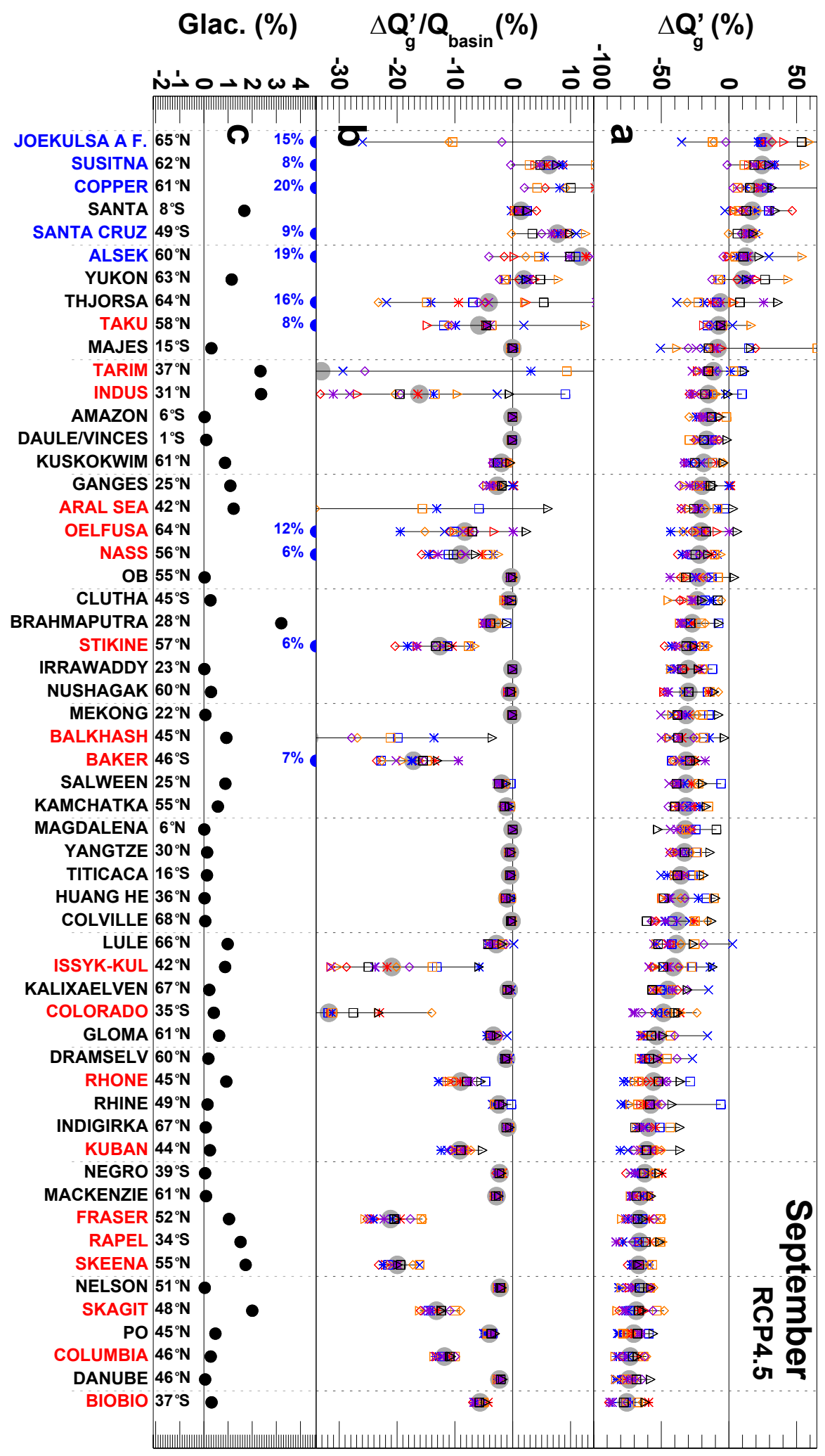

Supplementary Figure 8. Overview of results for all 56 investigated basins for September (March in the southern hemisphere). Results are based on projected glacier runoff changes over the period between 1990-2010 and 2080-2100. Individual GCMs (for RCP4.5) are indicated with symbols and the multi-GCM mean with a grey dot. a, Glacier runoff change $\Delta Q_{\mathrm{g}}^{\prime}$ (shifted with water transit time), $\mathbf{b}$, glacier runoff change relative to mean basin runoff, $\Delta Q_{\mathrm{g}}^{\prime} / Q_{\text {basin }}$, and $\mathbf{c}$, basin glacierization. Blue dots indicate values beyond the plotted range. Catchments are ordered according to $\Delta Q_{\mathrm{g}}^{\prime}$. Blue basin names indicate cases where glacier runoff is projected to increase by $>5 \%$ of basin runoff $\left(\Delta Q_{\mathrm{g}}^{\prime} / Q_{\mathrm{basin}}>0.05\right)$, while names in red mark basins where $\Delta Q_{\mathrm{g}}^{\prime} / Q_{\text {basin }}<-0.05$. 

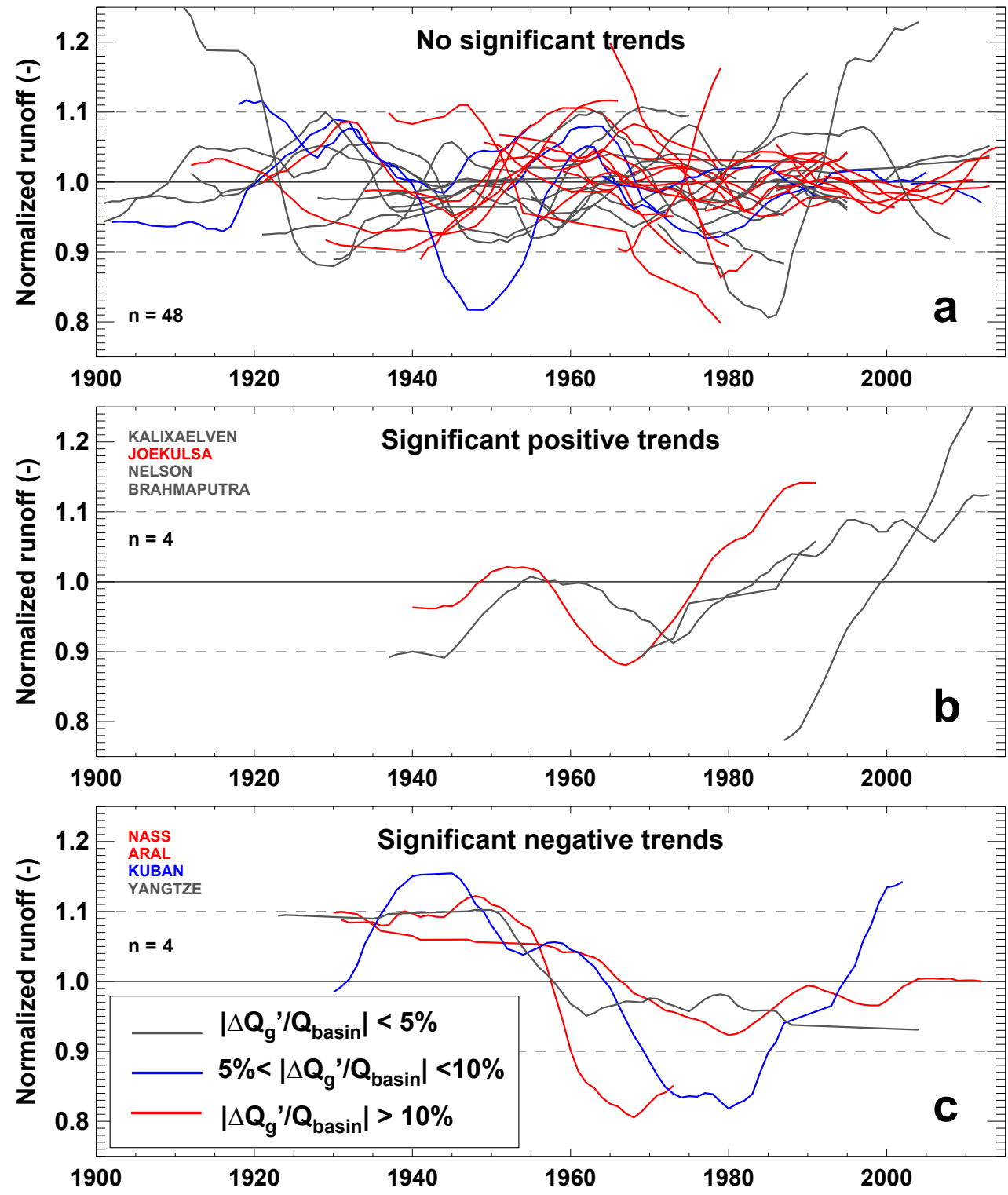

Supplementary Figure 9. Time series of annual runoff observations for all 56 investigated river basins ${ }^{5,6}$. 11-year running means normalized to their period means are plotted for all basins that show, $\mathbf{a}$, no temporal trend, $\mathbf{b}$, a significant positive, and $\mathbf{c}$, a significant negative trend. Trends were calculated using the Mann-Kendall test and significance was evaluated at the $p<0.05$ level. Colours refer to three ranges of $\left|\Delta Q_{\mathrm{g}}^{\prime} / Q_{\text {basin }}\right|$ distinguishing basins with negligible, moderate and large fractions of glacier runoff changes relative to total basin runoff. $92 \%$ of the basins with $\left|\Delta Q_{\mathrm{g}}^{\prime} / Q_{\text {basin }}\right|>10 \%$ show no significant trend in annual runoff. The smoothed runoff series rarely exceed $\pm 10 \%$ of their period average (dashed lines). River basin names are listed for $\mathbf{b}$ and $\mathbf{c}$. 


\section{SUPPLEMENTARY TABLES}

Supplementary Table 1. Characteristics of all 56 investigated glacierized macroscale drainage basins. We analyze all basins $>5,000 \mathrm{~km}^{2}$ with $>30 \mathrm{~km}^{2}$ of ice and $>0.01 \%$ ice cover based on $\mathrm{GRDC}^{7}$. Ice-covered area $\left(A_{\text {glacier }}\right)$ according to the Randolph Glacier Inventory version $4.0^{8}$, total basin area $\left(A_{\text {basin }}\right)$, glacierization (Glac.), basin center-point latitude (lat.) and longitude (lon.) and population density ( $\left.\rho_{\mathrm{pop}}\right)$ in $2000^{9}$ are given. Transit times $\left(t_{\mathrm{w}}\right)$ of the glacier runoff from the initially glacierized area through the basin were estimated using the empirical approximation by Nieuwenhuyse ${ }^{10}$. Basins are ordered according to decreasing glacier area.

\begin{tabular}{|c|c|c|c|c|c|c|c|c|}
\hline Basin & $\begin{array}{r}A_{\text {glacier }} \\
\left(\mathrm{km}^{2}\right)\end{array}$ & $\begin{array}{l}A_{\text {basin }} \\
\left(\mathrm{km}^{2}\right)\end{array}$ & $\begin{array}{r}\text { Glac. } \\
(\%)\end{array}$ & $\begin{array}{r}\text { lat. } \\
(\mathrm{deg})\end{array}$ & $\begin{array}{r}\text { lon. } \\
(\mathrm{deg})\end{array}$ & $\begin{array}{r}\rho_{\text {pop }} \\
\text { (p. } \mathrm{km}^{-2} \text { ) } \\
\end{array}$ & $\begin{array}{r}t_{\mathrm{W}} \\
(\mathrm{d})\end{array}$ & Continent \\
\hline INDUS & $26,983.8$ & $1,139,075$ & 2.37 & 31 & 74 & 186.5 & 39 & Asia \\
\hline TARIM & $24,645.4$ & $1,051,731$ & 2.34 & 37 & 81 & 9.0 & 41 & Asia \\
\hline BRAHMAPUTRA & $16,606.7$ & 518,011 & 3.21 & 28 & 90 & 128.2 & 30 & Asia \\
\hline ARAL SEA & $15,176.7$ & $1,233,148$ & 1.23 & 42 & 67 & 33.5 & 45 & Asia \\
\hline COPPER & $12,996.0$ & 64,959 & 20.01 & 61 & -143 & 0.1 & 7 & North America \\
\hline GANGES & $11,216.0$ & $1,024,462$ & 1.09 & 25 & 82 & 434.6 & 33 & Asia \\
\hline YUKON & $9,535.4$ & 829,632 & 1.15 & 63 & -144 & 0.1 & 35 & North America \\
\hline ALSEK & $5,614.8$ & 28,422 & 19.76 & 60 & -137 & 0.0 & 4 & North America \\
\hline SUSITNA & $4,304.0$ & 49,470 & 8.70 & 62 & -149 & 0.1 & 6 & North America \\
\hline BALKHASH & $3,945.4$ & 423,657 & 0.93 & 45 & 78 & 11.9 & 34 & Asia \\
\hline STIKINE & $3,467.6$ & 51,147 & 6.78 & 57 & -129 & 0.0 & 6 & North America \\
\hline SANTA CRUZ & $3,027.8$ & 30,599 & 9.89 & -49 & -71 & 0.3 & 8 & South America \\
\hline FRASER & $2,495.1$ & 239,678 & 1.04 & 52 & -122 & 3.0 & 15 & North America \\
\hline BAKER & $2,372.3$ & 30,760 & 7.71 & -46 & -72 & 0.4 & 7 & South America \\
\hline YANGTZE & $2,317.4$ & $1,745,094$ & 0.13 & 30 & 106 & 217.4 & 33 & Asia \\
\hline SALWEEN & $2,295.9$ & 258,475 & 0.89 & 25 & 96 & 24.7 & 11 & Asia \\
\hline COLUMBIA & $1,878.4$ & 668,561 & 0.28 & 46 & -116 & 9.9 & 21 & North America \\
\hline ISSYK-KUL & $1,677.3$ & 191,032 & 0.88 & 42 & 73 & 16.9 & 36 & Asia \\
\hline AMAZON & $1,634.1$ & $5,880,854$ & 0.03 & -6 & -64 & 4.3 & 63 & South America \\
\hline COLORADO & $1,601.2$ & 390,631 & 0.41 & -35 & -67 & 6.9 & 24 & South America \\
\hline TAKU & $1,583.6$ & 17,967 & 8.81 & 58 & -132 & 0.0 & 7 & North America \\
\hline MACKENZIE & $1,519.2$ & $1,752,001$ & 0.09 & 61 & -120 & 0.2 & 48 & North America \\
\hline NASS & $1,337.3$ & 21,211 & 6.30 & 56 & -129 & 0.1 & 4 & North America \\
\hline THJORSA & $1,251.8$ & 7,527 & 16.63 & 64 & -19 & 0.3 & 2 & Europe \\
\hline JOEKULSA A F. & $1,098.6$ & 7,311 & 15.03 & 65 & -16 & 0.1 & 2 & Europe \\
\hline KUSKOKWIM & $1,032.8$ & 118,114 & 0.87 & 61 & -156 & 0.1 & 14 & North America \\
\hline RHONE & 904.2 & 97,485 & 0.93 & 45 & 5 & 101.6 & 8 & Europe \\
\hline SKEENA & 742.3 & 42,944 & 1.73 & 55 & -127 & 1.0 & 5 & North America \\
\hline OB & 739.5 & $2,701,040$ & 0.03 & 55 & 75 & 10.3 & 71 & Asia \\
\hline OELFUSA & 683.4 & 5,678 & 12.04 & 64 & -20 & 2.4 & 3 & Europe \\
\hline MEKONG & 485.7 & 787,256 & 0.06 & 22 & 101 & 72.4 & 25 & Asia \\
\hline DANUBE & 408.4 & 793,704 & 0.05 & 46 & 18 & 102.4 & 30 & Europe \\
\hline NELSON & 374.7 & $1,099,380$ & 0.03 & 51 & -101 & 5.1 & 40 & North America \\
\hline PO & 347.3 & 73,066 & 0.48 & 45 & 9 & 231.6 & 10 & Europe \\
\hline КАМСНАТКА & 312.7 & 54,103 & 0.58 & 55 & 159 & 0.5 & 8 & Asia \\
\hline RHINE & 285.0 & 190,522 & 0.15 & 49 & 7 & 317.5 & 13 & Europe \\
\hline GLOMA & 269.4 & 42,862 & 0.63 & 61 & 10 & 13.6 & 6 & Europe \\
\hline HUANG HE & 267.9 & 988,062 & 0.03 & 36 & 107 & 163.6 & 32 & Asia \\
\hline INDIGIRKA & 248.4 & 341,227 & 0.07 & 67 & 144 & 0.1 & 22 & Asia \\
\hline LULE & 247.2 & 25,127 & 0.98 & 66 & 18 & 1.0 & 6 & Europe \\
\hline RAPEL & 238.1 & 15,689 & 1.52 & -34 & -70 & 49.7 & 6 & South America \\
\hline SANTA & 198.9 & 11,882 & 1.67 & -8 & -77 & 45.8 & 5 & South America \\
\hline SKAGIT & 159.5 & 7,961 & 2.00 & 48 & -121 & 3.1 & 4 & North America \\
\hline KUBAN & 146.0 & 58,935 & 0.25 & 44 & 40 & 57.4 & 10 & Asia \\
\hline TITICACA & 134.5 & 107,215 & 0.13 & -16 & -68 & 24.5 & 14 & South America \\
\hline NUSHAGAK & 86.4 & 29,513 & 0.29 & 60 & -156 & 0.1 & 6 & North America \\
\hline BIOBIO & 76.2 & 24,108 & 0.32 & -37 & -71 & 20.9 & 5 & South America \\
\hline IRRAWADDY & 71.2 & 411,516 & 0.02 & 23 & 96 & 86.2 & 24 & Asia \\
\hline NEGRO & 64.1 & 130,062 & 0.05 & -39 & -68 & 5.6 & 16 & South America \\
\hline MAJES & 57.3 & 18,612 & 0.31 & -15 & -72 & 5.4 & 5 & South America \\
\hline CLUTHA & 46.5 & 17,118 & 0.27 & -45 & 169 & 1.8 & 3 & New Zealand \\
\hline DAULE/VINCES & 40.6 & 41,993 & 0.10 & -1 & -79 & 93.1 & 6 & South America \\
\hline KALIXAELVEN & 37.9 & 17,157 & 0.22 & 67 & 20 & 1.5 & 4 & Europe \\
\hline MAGDALENA & 33.3 & 261,204 & 0.01 & 6 & -74 & 104.7 & 14 & South America \\
\hline DRAMSELV & 32.1 & 17,364 & 0.19 & 60 & 9 & 8.8 & 4 & Europe \\
\hline COLVILLE & 31.9 & 57,544 & 0.06 & 68 & -154 & 0.0 & 9 & North America \\
\hline
\end{tabular}


Supplementary Table 2. Global Circulation Models from the CMIP5 project ${ }^{11}$ used in this study. Grid cell resolution and the responsible institutions and countries are listed.

\begin{tabular}{|c|c|c|c|}
\hline GCM & resolution & Institution & Country \\
\hline BCC-CSM1-1 & $2.81^{\circ} \times 2.81^{\circ}$ & Beijing Climate Center China Meteorological Administration & China \\
\hline CanESM2 & $2.81^{\circ} \times 2.81^{\circ}$ & Canadian Centre for Climate Modeling and Analysis & Canada \\
\hline CCSM4 & $0.90^{\circ} \times 1.25^{\circ}$ & National Center for Atmospheric Research & United States \\
\hline CNRM-CM5 & $1.41^{\circ} \times 1.41^{\circ}$ & $\begin{array}{l}\text { Centre National de Recherches Meteorologiques/Centre Europeen de } \\
\text { Recherche et Formation Avancees en Calcul Scientifique }\end{array}$ & France \\
\hline CSIRO-Mk3-6-0 & $1.88^{\circ} \times 1.88^{\circ}$ & $\begin{array}{l}\text { Commonwealth Scientific and Industrial Research Organization in col- } \\
\text { laboration with Queensland Climate Change Centre of Excellence }\end{array}$ & Australia \\
\hline GFDL-CM3 & $2.00^{\circ} \times 2.50^{\circ}$ & NASA Geophysical Fluid Dynamics Laboratory & Unites States \\
\hline GISS-E2-R & $2.00^{\circ} \times 2.50^{\circ}$ & NASA Goddard Institute for Space Studies & Unites States \\
\hline HadGEM2-ES & $1.24^{\circ} \times 1.88^{\circ}$ & Met Office Hadley Centre & $\begin{array}{l}\text { United King } \\
\text { dom }\end{array}$ \\
\hline INMCM4 & $1.50^{\circ} \times 2.00^{\circ}$ & Met Office Hadley Centre & Russia \\
\hline IPSL-CM5A-LR & $1.90^{\circ} \times 3.75^{\circ}$ & Institut Pierre-Simon Laplace & France \\
\hline MIROC-ESM & $2.81^{\circ} \times 2.81^{\circ}$ & $\begin{array}{l}\text { Japan Agency for Marine-Earth Science and Technology, Atmosphere } \\
\text { and Ocean Research Institute (University of Tokyo) and National Insti- } \\
\text { tute for Environmental Studies }\end{array}$ & Japan \\
\hline MPI-ESM-LR & $1.88^{\circ} \times 1.88^{\circ}$ & Max Planck Institute for Meteorology & Germany \\
\hline MRI-CGCM3 & $1.13^{\circ} \times 1.13^{\circ}$ & Meteorological Research Institute & Japan \\
\hline NorESM1-M & $1.88^{\circ} \times 1.88^{\circ}$ & Norwegian Climate Centre & Norway \\
\hline
\end{tabular}


Supplementary Table 3. Modelled timing of peak water and corresponding uncertainties for all 56 investigated macroscale drainage basins. Peak water, $P_{\mathrm{W}}$, refers to the year when modelled annual glacier runoff has reached a maximum as determined from an 11-year moving average. Results refer to multi-GCM means derived from three emission scenarios (RCP2.6, RCP4.5, RCP8.5). The total uncertainty, $\sigma_{\text {tot }}$, is obtained by combing individual error components based on error propagation assuming the terms to be independent of each other. $\sigma_{1}$ refers to the standard deviation of the results from 14 GCMs. $\sigma_{2}$ refers to the uncertainty in peak water due to errors in initial ice volume, while $\sigma_{3}$ is uncertainty resulting from two sets of experiments varying parameterizations in the model (energy-balance instead of degree-day model; volume-area scaling instead of retreat parameterization, see Methods). Values are given in the unit year. $\Delta Q_{\text {ann }}$ is the change in annual glacier runoff (in \%) between the period 1980-2000 and the year of peak water.

\begin{tabular}{|c|c|c|c|c|c|c|c|c|c|c|c|c|c|c|c|}
\hline \multirow[t]{2}{*}{ Basin } & \multicolumn{5}{|c|}{ RCP2.6 } & \multicolumn{5}{|c|}{ RCP4.5 } & \multicolumn{5}{|c|}{ RCP8.5 } \\
\hline & $P_{\mathrm{W}} \pm \sigma_{\mathrm{tot}}$ & $\begin{array}{c}\sigma_{1} \\
\text { (years) }\end{array}$ & $\sigma_{2}$ & $\sigma_{3}$ & $\begin{array}{r}\Delta Q_{\text {ann }} \\
(\%)\end{array}$ & $P_{\mathrm{W}} \pm \sigma_{\mathrm{tot}}$ & $\begin{array}{c}\sigma_{1} \\
\text { (years) }\end{array}$ & $\sigma_{2}$ & $\sigma_{3}$ & $\begin{array}{r}\Delta Q_{\mathrm{ann}} \\
(\%)\end{array}$ & $P_{\mathrm{W}} \pm \sigma_{\mathrm{tot}}$ & $\begin{array}{c}\sigma_{1} \\
\text { (years) }\end{array}$ & $\sigma_{2}$ & $\sigma_{3}$ & $\begin{array}{r}\Delta Q_{\text {ann }} \\
(\%)\end{array}$ \\
\hline INDUS & $2029 \pm 10$ & 10 & 1 & 1 & +26 & $2045 \pm 17$ & 17 & 1 & 4 & +32 & $2064 \pm 19$ & 18 & 6 & 1 & +48 \\
\hline TARIM & $2030 \pm 8$ & 6 & 2 & 5 & +43 & $2051 \pm 13$ & 11 & 6 & 5 & +53 & $2058 \pm 15$ & 14 & 4 & 5 & +67 \\
\hline BRAHMAPUTRA & $2030 \pm 18$ & 7 & 14 & 9 & +15 & $2049 \pm 18$ & 16 & 9 & 2 & +16 & $2049 \pm 30$ & 19 & 17 & 16 & +22 \\
\hline ARAL SEA & $2030 \pm 5$ & 5 & 2 & 1 & +37 & $2051 \pm 14$ & 14 & 3 & 0 & +42 & $2044 \pm 15$ & 15 & 5 & 0 & +53 \\
\hline COPPER & $2033 \pm 28$ & 24 & 0 & 15 & +40 & $2055 \pm 19$ & 19 & 0 & 0 & +51 & $2087 \pm 7$ & 7 & 0 & 0 & +88 \\
\hline GANGES & $2028 \pm 19$ & 19 & 0 & 5 & +15 & $2044 \pm 21$ & 21 & 3 & 0 & +19 & $2053 \pm 32$ & 28 & 12 & 10 & +25 \\
\hline YUKON & $2033 \pm 25$ & 25 & 0 & 0 & +47 & $2054 \pm 19$ & 19 & 0 & 0 & +56 & $2094 \pm 11$ & 11 & 0 & 0 & +112 \\
\hline ALSEK & $2033 \pm 21$ & 21 & 0 & 0 & +36 & $2055 \pm 22$ & 22 & 0 & 0 & +44 & $2087 \pm 10$ & 10 & 0 & 0 & +71 \\
\hline SUSITNA & $2033 \pm 19$ & 19 & 6 & 0 & +36 & $2079 \pm 18$ & 18 & 0 & 0 & +46 & $2094 \pm 9$ & 9 & 0 & 2 & +85 \\
\hline BALKHASH & $2030 \pm 7$ & 7 & 2 & 2 & +37 & $2051 \pm 12$ & 11 & 0 & 5 & +42 & $2049 \pm 20$ & 18 & 1 & 10 & +53 \\
\hline STIKINE & $2025 \pm 17$ & 16 & 7 & 0 & +20 & $2026 \pm 15$ & 14 & 6 & 2 & +18 & $2048 \pm 22$ & 18 & 14 & 0 & +21 \\
\hline SANTA CRUZ & $2050 \pm 18$ & 18 & 1 & 0 & +14 & $2091 \pm 24$ & 20 & 14 & 0 & +21 & $2096 \pm 9$ & 8 & 3 & 3 & +48 \\
\hline FRASER & $2017 \pm 3$ & 3 & 0 & 0 & +12 & $2016 \pm 14$ & 11 & 10 & 0 & +11 & $2010 \pm 13$ & 11 & 7 & 5 & +11 \\
\hline BAKER & $2015 \pm 18$ & 8 & 15 & 6 & +5 & $2016 \pm 13$ & 8 & 9 & 7 & +5 & $2020 \pm 16$ & 15 & 4 & 5 & +5 \\
\hline YANGTZE & $2028 \pm 15$ & 6 & 8 & 12 & +20 & $2028 \pm 13$ & 12 & 1 & 5 & +21 & $2044 \pm 19$ & 19 & 2 & 2 & +28 \\
\hline SALWEEN & $2028 \pm 11$ & 6 & 7 & 7 & +20 & $2049 \pm 19$ & 18 & 1 & 7 & +20 & $2043 \pm 19$ & 19 & 6 & 0 & +26 \\
\hline COLUMBIA & $2010 \pm 10$ & 7 & 8 & 0 & +7 & $2010 \pm 14$ & 8 & 12 & 0 & +6 & $2010 \pm 6$ & 6 & 0 & 0 & +7 \\
\hline ISSYK-KUL & $2028 \pm 9$ & 9 & 3 & 0 & +35 & $2025 \pm 10$ & 10 & 0 & 0 & +35 & $2042 \pm 17$ & 17 & 3 & 0 & +44 \\
\hline AMAZON & $2010 \pm 3$ & 2 & 2 & 2 & +34 & $2011 \pm 7$ & 4 & 3 & 6 & +35 & $2012 \pm 24$ & 3 & 1 & 24 & +35 \\
\hline COLORADO & $2010 \pm 13$ & 4 & 9 & 9 & +17 & $2011 \pm 10$ & 9 & 1 & 5 & +17 & $2011 \pm 15$ & 13 & 4 & 7 & +17 \\
\hline TAKU & $2027 \pm 5$ & 4 & 3 & 0 & +25 & $2055 \pm 12$ & 12 & 0 & 0 & +25 & $2077 \pm 13$ & 13 & 3 & 0 & +40 \\
\hline MACKENZIE & $2011 \pm 18$ & 7 & 9 & 15 & +7 & $2013 \pm 10$ & 8 & 6 & 0 & +8 & $2011 \pm 8$ & 8 & 1 & 0 & +8 \\
\hline NASS & $2025 \pm 19$ & 19 & 0 & 0 & +22 & $2055 \pm 16$ & 16 & 1 & 0 & +22 & $2069 \pm 13$ & 10 & 8 & 4 & +32 \\
\hline THJORSA & $2046 \pm 21$ & 20 & 9 & 0 & +50 & $2042 \pm 20$ & 20 & 0 & 0 & +62 & $2071 \pm 21$ & 18 & 6 & 11 & +78 \\
\hline JOEKULSA A F. & $2047 \pm 21$ & 19 & 0 & 11 & +64 & $2064 \pm 22$ & 22 & 0 & 0 & +79 & $2080 \pm 20$ & 14 & 12 & 8 & +124 \\
\hline KUSKOKWIM & $2030 \pm 21$ & 21 & 0 & 0 & +37 & $2047 \pm 20$ & 20 & 0 & 0 & +39 & $2057 \pm 11$ & 9 & 6 & 2 & +48 \\
\hline RHONE & $2006 \pm 14$ & 9 & 11 & 0 & +28 & $2006 \pm 7$ & 7 & 2 & 0 & +27 & $2006 \pm 24$ & 18 & 16 & 0 & +28 \\
\hline SKEENA & $2009 \pm 6$ & 6 & 0 & 0 & +9 & $2010 \pm 7$ & 7 & 0 & 0 & +9 & $2010 \pm 6$ & 6 & 1 & 0 & +9 \\
\hline OB & $2004 \pm 10$ & 10 & 0 & 0 & +14 & $2004 \pm 14$ & 12 & 4 & 7 & +12 & $2006 \pm 27$ & 27 & 1 & 2 & +16 \\
\hline OELFUSA & $2045 \pm 23$ & 18 & 12 & 8 & +32 & $2042 \pm 20$ & 20 & 6 & 2 & +38 & $2048 \pm 25$ & 19 & 11 & 12 & +45 \\
\hline MEKONG & $2029 \pm 17$ & 6 & 13 & 10 & +25 & $2049 \pm 20$ & 20 & 0 & 0 & +26 & $2043 \pm 23$ & 23 & 6 & 0 & +33 \\
\hline DANUBE & $2006 \pm 7$ & 4 & 6 & 0 & +24 & $2006 \pm 4$ & 4 & 1 & 0 & +23 & $2006 \pm 2$ & 1 & 2 & 1 & +23 \\
\hline NELSON & $2013 \pm 11$ & 8 & 8 & 0 & +7 & $2014 \pm 17$ & 10 & 13 & 5 & +6 & $2010 \pm 10$ & 9 & 6 & 0 & +7 \\
\hline $\mathrm{PO}$ & $2006 \pm 7$ & 5 & 6 & 0 & +26 & $2006 \pm 3$ & 3 & 0 & 0 & +25 & $2006 \pm 6$ & 2 & 6 & 0 & +26 \\
\hline КАМСНАТКА & $2025 \pm 6$ & 6 & 0 & 0 & +26 & $2038 \pm 17$ & 13 & 12 & 0 & +24 & $2030 \pm 18$ & 18 & 1 & 5 & +32 \\
\hline RHINE & $2006 \pm 18$ & 17 & 7 & 3 & +21 & $2006 \pm 15$ & 15 & 2 & 2 & +20 & $2005 \pm 21$ & 17 & 13 & 0 & +20 \\
\hline GLOMA & $2010 \pm 9$ & 5 & 8 & 0 & +26 & $2026 \pm 16$ & 10 & 10 & 9 & +23 & $2016 \pm 18$ & 17 & 6 & 0 & +26 \\
\hline HUANG HE & $2029 \pm 6$ & 5 & 4 & 2 & +36 & $2051 \pm 17$ & 17 & 1 & 1 & +40 & $2043 \pm 20$ & 20 & 1 & 0 & +48 \\
\hline INDIGIRKA & $2004 \pm 8$ & 8 & 1 & 0 & +15 & $2004 \pm 12$ & 11 & 6 & 3 & +12 & $2006 \pm 15$ & 15 & 1 & 1 & +16 \\
\hline LULE & $2022 \pm 22$ & 22 & 4 & 0 & +29 & $2027 \pm 12$ & 11 & 5 & 4 & +30 & $2029 \pm 26$ & 25 & 10 & 0 & +29 \\
\hline RAPEL & $2010 \pm 13$ & 4 & 6 & 11 & +12 & $2011 \pm 11$ & 10 & 4 & 4 & +12 & $2010 \pm 16$ & 10 & 9 & 9 & +12 \\
\hline SANTA & $2011 \pm 21$ & 5 & 21 & 3 & +50 & $2012 \pm 25$ & 7 & 18 & 17 & +53 & $2016 \pm 29$ & 29 & 1 & 2 & +53 \\
\hline SKAGIT & $2008 \pm 6$ & 6 & 2 & 0 & +12 & $2008 \pm 13$ & 12 & 5 & 0 & +11 & $2007 \pm 7$ & 7 & 0 & 0 & +11 \\
\hline KUBAN & $2002 \pm 7$ & 7 & 0 & 0 & +16 & $2003 \pm 6$ & 4 & 4 & 4 & +17 & $2013 \pm 8$ & 8 & 2 & 0 & +17 \\
\hline TITICACA & $2011 \pm 5$ & 4 & 2 & 3 & +42 & $2012 \pm 9$ & 4 & 1 & 8 & +43 & $2012 \pm 7$ & 4 & 0 & 6 & +43 \\
\hline NUSHAGAK & $2027 \pm 14$ & 14 & 1 & 0 & +34 & $2038 \pm 12$ & 12 & 2 & 0 & +31 & $2032 \pm 15$ & 15 & 3 & 0 & +34 \\
\hline BIOBIO & $2002 \pm 3$ & 3 & 2 & 1 & +9 & $2002 \pm 4$ & 3 & 3 & 1 & +8 & $2003 \pm 6$ & 3 & 5 & 2 & +9 \\
\hline IRRAWADDY & $2000 \pm 17$ & 17 & 0 & 0 & +7 & $2000 \pm 35$ & 35 & 0 & 0 & +8 & $2095 \pm 45$ & 45 & 0 & 0 & +10 \\
\hline NEGRO & $2002 \pm 12$ & 11 & 4 & 4 & +5 & $2002 \pm 11$ & 10 & 3 & 5 & +4 & $2003 \pm 11$ & 11 & 4 & 2 & +5 \\
\hline MAJES & $2026 \pm 7$ & 4 & 3 & 6 & +79 & $2038 \pm 5$ & 4 & 1 & 3 & +97 & $2046 \pm 21$ & 21 & 3 & 4 & +119 \\
\hline CLUTHA & $2038 \pm 17$ & 17 & 0 & 0 & +22 & $2028 \pm 12$ & 12 & 0 & 0 & +21 & $2040 \pm 21$ & 21 & 0 & 0 & +26 \\
\hline DAULE/VINCES & $1980 \pm 0$ & 0 & 0 & 0 & +14 & $1980 \pm 0$ & 0 & 0 & 0 & +15 & $1980 \pm 0$ & 0 & 0 & 0 & +15 \\
\hline KALIXAELVEN & $2019 \pm 10$ & 6 & 4 & 8 & +25 & $2024 \pm 23$ & 9 & 14 & 16 & +23 & $2014 \pm 27$ & 25 & 11 & 6 & +26 \\
\hline MAGDALENA & $1981 \pm 6$ & 0 & 0 & 6 & +22 & $1981 \pm 14$ & 0 & 0 & 14 & +22 & $1981 \pm 14$ & 0 & 0 & 14 & +22 \\
\hline DRAMSELV & $2010 \pm 8$ & 4 & 8 & 0 & +20 & $2012 \pm 14$ & 10 & 10 & 0 & +17 & $2013 \pm 16$ & 16 & 1 & 1 & +19 \\
\hline COLVILLE & $2026 \pm 13$ & 13 & 0 & 0 & +40 & $2026 \pm 20$ & 18 & 10 & 0 & +42 & $2040 \pm 27$ & 16 & 21 & 8 & +42 \\
\hline
\end{tabular}


Supplementary Table 4. Projected monthly glacier runoff changes $(\%), \Delta Q_{\mathrm{g}}$, including uncertainties. $\Delta Q_{\mathrm{g}}$ refers to the change in monthly glacier runoff between the periods 1990-2010 and 2080-2100, and is listed for the months June to September (December to March for the southern hemisphere, marked with *). Results refer to multi-GCM means and are given for three emission scenarios (RCP2.6, RCP4.5 and RCP8.5). Numbers in bold indicate cases with $\left|\Delta Q_{\mathrm{g}}\right|$ exceeding the uncertainty indicating that the sign of modelled runoff change is robust. Basins are ordered according to decreasing glacier area.

\begin{tabular}{|c|c|c|c|c|c|c|c|c|c|c|c|c|}
\hline \multirow[t]{2}{*}{ Basin } & \multicolumn{4}{|c|}{ RCP2.6 } & \multicolumn{4}{|c|}{ RCP4.5 } & \multicolumn{4}{|c|}{ RCP8.5 } \\
\hline & \multicolumn{3}{|c|}{$(\%)$} & $\Delta Q_{\mathrm{Sep}}$ & $\Delta Q_{\text {Jun }}$ & \multicolumn{2}{|c|}{$(\%)$} & $\Delta Q_{\mathrm{Sep}}$ & $\Delta Q_{\text {Jun }}$ & \multicolumn{2}{|c|}{$(\%)$} & $\Delta Q_{\mathrm{Sep}}$ \\
\hline INDUS & $+\mathbf{3 7} \pm \mathbf{2 4}$ & $-4 \pm 7$ & $\mathbf{- 2 0} \pm \mathbf{1 0}$ & $-21 \pm 15$ & $+87 \pm 25$ & $-2 \pm 9$ & $-20 \pm 11$ & $-15 \pm 16$ & $+128 \pm 33$ & $-9 \pm 19$ & $-\mathbf{- 2 5} \pm 18$ & $+7 \pm 28$ \\
\hline TARIM & $+35 \pm 15$ & $-1 \pm 5$ & $-21 \pm 11$ & $-22 \pm 10$ & $+79 \pm 13$ & $+1 \pm 10$ & $-18 \pm 13$ & $-9 \pm 13$ & $+\mathbf{9 5} \pm 26$ & $-13 \pm 17$ & $-24 \pm 17$ & $+19 \pm 29$ \\
\hline BRAHMAPUTRA & $+13 \pm 13$ & $-4 \pm 4$ & $-21 \pm 10$ & $-21 \pm 10$ & $+23 \pm 9$ & $-9 \pm 6$ & $-27 \pm 9$ & $-24 \pm 8$ & $+27 \pm 34$ & $-21 \pm 16$ & $-35 \pm 13$ & $-25 \pm 16$ \\
\hline ARAL SEA & $\mathbf{+ 3 5} \pm \mathbf{1 4}$ & $-4 \pm 4$ & $-28 \pm 11$ & $-29 \pm 11$ & $+74 \pm 13$ & $-7 \pm 9$ & $-33 \pm 12$ & $-23 \pm 12$ & $+82 \pm 23$ & $-27 \pm 15$ & $-42 \pm 13$ & $-10 \pm 20$ \\
\hline COPPER & $+\mathbf{+ 2 7} \pm 19$ & $+6 \pm 9$ & $-1 \pm 8$ & $+12 \pm 12$ & $+42 \pm 14$ & $+\mathbf{1 3} \pm \mathbf{1 0}$ & $+7 \pm 14$ & $+33 \pm 24$ & $+69 \pm 23$ & $+27 \pm 13$ & $+24 \pm 16$ & $+71 \pm 26$ \\
\hline GANGES & $+12 \pm 21$ & $-8 \pm 7$ & $-19 \pm 12$ & $-17 \pm 18$ & $\boldsymbol{+ 3 5} \pm 16$ & $-4 \pm 10$ & $-21 \pm 9$ & $-11 \pm 11$ & $\mathbf{+ 5 2} \pm 36$ & $-8 \pm 25$ & $-23 \pm 24$ & $-3 \pm 20$ \\
\hline YUKON & $+\mathbf{3 1} \pm \mathbf{2 0}$ & $+5 \pm 7$ & $-4 \pm 10$ & $+19 \pm 14$ & $+51 \pm 16$ & $+16 \pm 7$ & $+10 \pm 12$ & $\mathbf{+ 5 5} \pm \mathbf{2 5}$ & $+\mathbf{9 5} \pm 15$ & $+42 \pm 8$ & $+43 \pm 12$ & $+161 \pm 16$ \\
\hline ALSEK & $+19 \pm 25$ & $-0 \pm 11$ & $-\mathbf{- 1 1} \pm \mathbf{8}$ & $+6 \pm 13$ & $\mathbf{+ 2 8} \pm \mathbf{2 0}$ & $+4 \pm 11$ & $-7 \pm 9$ & $+17 \pm 18$ & $\mathbf{+ 4 1} \pm 34$ & $+9 \pm 14$ & $+0 \pm 18$ & $+\mathbf{3 5} \pm \mathbf{2 7}$ \\
\hline SUSITNA & $+27 \pm 12$ & $+2 \pm 5$ & $-1 \pm 9$ & $+11 \pm 11$ & $+42 \pm 10$ & $+8 \pm 6$ & $+6 \pm 9$ & $+\mathbf{3 6} \pm 17$ & $+69 \pm 12$ & $+\mathbf{2 3} \pm 10$ & $+\mathbf{2 5} \pm \mathbf{1 3}$ & $+92 \pm 16$ \\
\hline BALKHASH & $+31 \pm 13$ & $-4 \pm 4$ & $-29 \pm 11$ & $-29 \pm 12$ & $+65 \pm 13$ & $-9 \pm 10$ & $-34 \pm 12$ & $-23 \pm 14$ & $+66 \pm 23$ & $\mathbf{- 3 0} \pm \mathbf{1 7}$ & $-43 \pm 11$ & $-10 \pm 21$ \\
\hline STIKINE & $+15 \pm 13$ & $-13 \pm 8$ & $-38 \pm 14$ & $-23 \pm 13$ & $+23 \pm 6$ & $-19 \pm 8$ & $-44 \pm 10$ & $-24 \pm 13$ & $+9 \pm 21$ & $-39 \pm 18$ & $-52 \pm 12$ & $-26 \pm 14$ \\
\hline SANTA CRUZ* & $+0 \pm 6$ & $+0 \pm 6$ & $+3 \pm 4$ & $+3 \pm 5$ & $+10 \pm 6$ & $+8 \pm 5$ & $+10 \pm 7$ & $+16 \pm 8$ & $+26 \pm 7$ & $+19 \pm 7$ & $+18 \pm 10$ & $+\mathbf{3 1} \pm \mathbf{1 1}$ \\
\hline FRASER & $+14 \pm 10$ & $-15 \pm 6$ & $\mathbf{- 5 5} \pm \mathbf{1 5}$ & $-\mathbf{5 9} \pm \mathbf{1 6}$ & $+30 \pm 9$ & $-22 \pm 11$ & $-66 \pm 9$ & $-66 \pm 7$ & $+24 \pm 12$ & $-48 \pm 17$ & $-80 \pm 7$ & $-73 \pm 6$ \\
\hline BAKER ${ }^{*}$ & $+0 \pm 5$ & $-12 \pm 6$ & $-24 \pm 8$ & $-\mathbf{2 8} \pm \mathbf{1 0}$ & $+3 \pm 6$ & $-18 \pm 6$ & $-32 \pm 7$ & $-31 \pm 8$ & $-14 \pm 11$ & $-38 \pm 9$ & $-47 \pm 8$ & $-40 \pm 9$ \\
\hline YANGTZE & $+14 \pm 19$ & $-11 \pm 10$ & $\mathbf{- 3 1} \pm \mathbf{1 0}$ & $-24 \pm 10$ & $+34 \pm 5$ & $-16 \pm 6$ & $-35 \pm 7$ & $-17 \pm 9$ & $+32 \pm 52$ & $\mathbf{- 3 1} \pm \mathbf{1 1}$ & $-43 \pm 9$ & $-14 \pm 19$ \\
\hline SALWEEN & $+19 \pm 12$ & $-3 \pm 4$ & $-27 \pm 10$ & $-28 \pm 11$ & $+\mathbf{4 1} \pm 8$ & $-7 \pm 6$ & $-34 \pm 9$ & $-29 \pm 9$ & $+\mathbf{3 7} \pm \mathbf{2 7}$ & $\mathbf{- 3 0} \pm \mathbf{1 4}$ & $-46 \pm 10$ & $-29 \pm 13$ \\
\hline COLUMBIA & $+17 \pm 10$ & $-22 \pm 10$ & $-64 \pm 19$ & $-68 \pm 18$ & $+33 \pm 14$ & $-33 \pm 21$ & $-74 \pm 9$ & $-70 \pm 8$ & $+26 \pm 12$ & $-\mathbf{5 7} \pm 17$ & $-83 \pm 6$ & $-75 \pm 5$ \\
\hline ISSYK-KUL & $+38 \pm 15$ & $-6 \pm 5$ & $-38 \pm 14$ & $-43 \pm 13$ & $+76 \pm 16$ & $-\mathbf{1 4} \pm \mathbf{1 1}$ & $-47 \pm 14$ & $-39 \pm 13$ & $+68 \pm 27$ & $-42 \pm 16$ & $-59 \pm 12$ & $-33 \pm 15$ \\
\hline AMAZON* & $-22 \pm 11$ & $-19 \pm 12$ & $\mathbf{- 2 0} \pm \mathbf{1 0}$ & $-25 \pm 10$ & $-22 \pm 10$ & $-16 \pm 14$ & $-17 \pm 14$ & $-23 \pm 15$ & $-22 \pm 19$ & $-12 \pm 24$ & $-12 \pm 28$ & $-21 \pm 19$ \\
\hline COLORADO* & $+\mathbf{1 4} \pm 10$ & $-28 \pm 9$ & $-36 \pm 17$ & $-46 \pm 16$ & $+26 \pm 13$ & $\mathbf{- 3 8} \pm \mathbf{1 3}$ & $-48 \pm 15$ & $-49 \pm 17$ & $+15 \pm 24$ & $-55 \pm 14$ & $-58 \pm 14$ & $-\mathbf{5 0} \pm \mathbf{1 5}$ \\
\hline TAKU & $+12 \pm 11$ & $-12 \pm 13$ & $\mathbf{- 2 7} \pm \mathbf{1 8}$ & $-6 \pm 14$ & $+19 \pm 9$ & $-12 \pm 13$ & $-26 \pm 12$ & $+3 \pm 13$ & $+18 \pm 25$ & $-12 \pm 25$ & $-19 \pm 13$ & $\boldsymbol{+ 2 1} \pm \mathbf{1 2}$ \\
\hline MACKENZIE & $+4 \pm 8$ & $-49 \pm 14$ & $-73 \pm 19$ & $-63 \pm 18$ & $+12 \pm 9$ & $-\mathbf{5 8} \pm \mathbf{1 0}$ & $-76 \pm 4$ & $-56 \pm 8$ & $+0 \pm 18$ & $-67 \pm 6$ & $-79 \pm 4$ & $-43 \pm 12$ \\
\hline NASS & $+19 \pm 13$ & $-8 \pm 5$ & $-29 \pm 12$ & $-16 \pm 14$ & $+25 \pm 7$ & $-15 \pm 6$ & $-36 \pm 13$ & $-19 \pm 18$ & $+10 \pm 9$ & $-\mathbf{3 3} \pm \mathbf{1 4}$ & $-46 \pm 18$ & $-23 \pm 22$ \\
\hline THJORSA & $+9 \pm 16$ & $-18 \pm 13$ & $-26 \pm 13$ & $-14 \pm 17$ & $+10 \pm 19$ & $-\mathbf{1 4} \pm 14$ & $-20 \pm 11$ & $-5 \pm 18$ & $+14 \pm 19$ & $-4 \pm 19$ & $-10 \pm 19$ & $+11 \pm 22$ \\
\hline JOEKULSA A F. & $+15 \pm 21$ & $+3 \pm 12$ & $-2 \pm 13$ & $+11 \pm 21$ & $+\mathbf{3 3} \pm \mathbf{3 0}$ & $+15 \pm 21$ & $+9 \pm 15$ & $+29 \pm 32$ & $+56 \pm 41$ & $+35 \pm 31$ & $+25 \pm 31$ & $+52 \pm 40$ \\
\hline KUSKOKWIM & $\mathbf{+ 2 8} \pm \mathbf{1 7}$ & $-12 \pm 4$ & $-\mathbf{2 8} \pm \mathbf{1 0}$ & $-11 \pm 12$ & $+43 \pm 10$ & $-12 \pm 7$ & $-\mathbf{3 0} \pm \mathbf{1 1}$ & $+13 \pm 19$ & $+55 \pm 12$ & $-\mathbf{- 1 8} \pm 17$ & $-\mathbf{3 1} \pm \mathbf{1 9}$ & $+45 \pm 23$ \\
\hline RHONE & $+9 \pm 15$ & $-18 \pm 12$ & $-\mathbf{5 2} \pm \mathbf{1 5}$ & $-47 \pm 16$ & $+30 \pm 9$ & $-22 \pm 11$ & $-61 \pm 12$ & $-52 \pm 14$ & $+\mathbf{3 1} \pm \mathbf{1 7}$ & $-56 \pm 19$ & $-76 \pm 11$ & $-62 \pm 15$ \\
\hline SKEENA & $+13 \pm 10$ & $-20 \pm 11$ & $-63 \pm 20$ & $-61 \pm 17$ & $+22 \pm 6$ & $-34 \pm 12$ & $-74 \pm 9$ & $-65 \pm 5$ & $-3 \pm 32$ & $-63 \pm 23$ & $-84 \pm 6$ & $-67 \pm 3$ \\
\hline $\mathrm{OB}$ & $+24 \pm 8$ & $-\mathbf{3 0} \pm 12$ & $-55 \pm 17$ & $\mathbf{- 5 3} \pm \mathbf{1 7}$ & $+41 \pm 9$ & $\mathbf{- 3 8} \pm \mathbf{1 3}$ & $-59 \pm 10$ & $-44 \pm 11$ & $+36 \pm 19$ & $\mathbf{- 5 4} \pm \mathbf{1 5}$ & $-65 \pm 10$ & $-23 \pm 18$ \\
\hline OELFUSA & $+13 \pm 15$ & $-\mathbf{2 0} \pm 12$ & $-32 \pm 14$ & $-21 \pm 16$ & $+9 \pm 12$ & $-27 \pm 13$ & $-\mathbf{3 1} \pm \mathbf{1 3}$ & $-19 \pm 13$ & $-9 \pm 22$ & $\mathbf{- 3 0} \pm \mathbf{1 6}$ & $-\mathbf{3 0} \pm 16$ & $-15 \pm 18$ \\
\hline MEKONG & $+\mathbf{2 0} \pm \mathbf{1 5}$ & $-5 \pm 5$ & $-27 \pm 10$ & $-\mathbf{2 0} \pm \mathbf{1 8}$ & $+45 \pm 9$ & $-\mathbf{- 1 0} \pm \mathbf{8}$ & $-33 \pm 8$ & $-16 \pm 9$ & $+44 \pm 29$ & $-29 \pm 18$ & $-44 \pm 17$ & $-15 \pm 16$ \\
\hline DANUBE & $+16 \pm 12$ & $-23 \pm 14$ & $-63 \pm 18$ & $-63 \pm 18$ & $+29 \pm 10$ & $-38 \pm 7$ & $-74 \pm 8$ & $-67 \pm 7$ & $+10 \pm 27$ & $-67 \pm 13$ & $-81 \pm 5$ & $-70 \pm 9$ \\
\hline NELSON & $+\mathbf{1 5} \pm 10$ & $-39 \pm 15$ & $-67 \pm 19$ & $-66 \pm 18$ & $+27 \pm 24$ & $-51 \pm 22$ & $-73 \pm 7$ & $-65 \pm 9$ & $+11 \pm 25$ & $-67 \pm 16$ & $-\mathbf{8 0} \pm \mathbf{8}$ & $-67 \pm 7$ \\
\hline PO & $+14 \pm 13$ & $-20 \pm 12$ & $-64 \pm 17$ & $-61 \pm 18$ & $+31 \pm 9$ & $-\mathbf{3 3} \pm \mathbf{1 0}$ & $-74 \pm 8$ & $-67 \pm 9$ & $+18 \pm 21$ & $-67 \pm 14$ & $-83 \pm 5$ & $-72 \pm 9$ \\
\hline КАМСНАТКА & $+\mathbf{5 3} \pm \mathbf{2 0}$ & $-21 \pm 10$ & $-42 \pm 16$ & $-\mathbf{3 5} \pm \mathbf{1 4}$ & $+92 \pm 26$ & $-22 \pm 12$ & $-41 \pm 14$ & $-18 \pm 18$ & $+118 \pm 32$ & $\mathbf{- 3 8} \pm \mathbf{1 7}$ & $-45 \pm 18$ & $+29 \pm 48$ \\
\hline RHINE & $+10 \pm 15$ & $-8 \pm 9$ & $-47 \pm 16$ & $-49 \pm 16$ & $\mathbf{+ 3 0} \pm 9$ & $-13 \pm 7$ & $-59 \pm 11$ & $-56 \pm 12$ & $6 \pm 14$ & $-51 \pm \mathbf{2 0}$ & $-\mathbf{7 8} \pm \mathbf{1 0}$ & $-\mathbf{7 0} \pm \mathbf{1 3}$ \\
\hline GLOMA & $\mathbf{+ 3 1} \pm \mathbf{1 5}$ & $-\mathbf{1 5} \pm 10$ & $-59 \pm 21$ & $-\mathbf{5 7} \pm 18$ & $+47 \pm 17$ & $-\mathbf{2 3} \pm 14$ & $-60 \pm 14$ & $-50 \pm 12$ & $\mathbf{+ 6 1} \pm 23$ & $-39 \pm 26$ & $-70 \pm 12$ & $-45 \pm 11$ \\
\hline HUANG HE & $+\mathbf{3 6} \pm 14$ & $-4 \pm 5$ & $-\mathbf{3 4} \pm \mathbf{1 3}$ & $-\mathbf{3 7} \pm \mathbf{1 3}$ & $+\mathbf{7 3} \pm 13$ & $-8 \pm 12$ & $-37 \pm 14$ & $-25 \pm 15$ & $+\mathbf{7 5} \pm \mathbf{2 4}$ & $\mathbf{- 3 1} \pm \mathbf{1 5}$ & $-46 \pm 9$ & $-8 \pm 14$ \\
\hline INDIGIRKA & $+28 \pm 9$ & $-\mathbf{3 1} \pm \mathbf{1 3}$ & $-58 \pm 18$ & $-56 \pm 18$ & $+45 \pm 11$ & $-\mathbf{3 7} \pm \mathbf{1 3}$ & $-61 \pm 8$ & $-45 \pm 13$ & $+41 \pm 21$ & $-56 \pm 13$ & $-67 \pm 8$ & $-23 \pm 21$ \\
\hline LULE & $+25 \pm 11$ & $-2 \pm 10$ & $-45 \pm 21$ & $-\mathbf{3 4} \pm \mathbf{1 6}$ & $+45 \pm 13$ & $-11 \pm 13$ & $-55 \pm 14$ & $-\mathbf{3 1} \pm \mathbf{2 0}$ & $+58 \pm 32$ & $-35 \pm 21$ & $-68 \pm 8$ & $-31 \pm 19$ \\
\hline RAPEL* & $+2 \pm 7$ & $-28 \pm 9$ & $-47 \pm 16$ & $-60 \pm 19$ & $+10 \pm 11$ & $-41 \pm 12$ & $-62 \pm 14$ & $-67 \pm 17$ & $-6 \pm 23$ & $-65 \pm 13$ & $-\mathbf{7 8} \pm \mathbf{1 0}$ & $-77 \pm 14$ \\
\hline SANTA* ${ }^{*}$ & $+12 \pm 20$ & $+12 \pm 15$ & $+20 \pm 23$ & $+6 \pm 13$ & $+16 \pm 17$ & $+23 \pm 22$ & $+\mathbf{3 8} \pm 34$ & $+14 \pm 15$ & $+34 \pm 50$ & $+39 \pm 75$ & $+55 \pm 86$ & $+28 \pm 44$ \\
\hline SKAGIT & $+8 \pm 9$ & $-5 \pm 5$ & $-43 \pm 13$ & $-61 \pm 18$ & $+23 \pm 11$ & $-3 \pm 5$ & $-56 \pm 12$ & $-71 \pm 8$ & $+13 \pm 13$ & $-39 \pm 26$ & $-80 \pm 12$ & $-83 \pm 5$ \\
\hline KUBAN & $+31 \pm 16$ & $-2 \pm 9$ & $-45 \pm 16$ & $-\mathbf{5 5} \pm \mathbf{2 0}$ & $\mathbf{+ 3 8} \pm \mathbf{1 0}$ & $-8 \pm 11$ & $-\mathbf{5 7} \pm 10$ & $-64 \pm 7$ & $+53 \pm 16$ & $-44 \pm 12$ & $-77 \pm 10$ & $-73 \pm 12$ \\
\hline TITICACA* & $-34 \pm 14$ & $-28 \pm 13$ & $-32 \pm 13$ & $-\mathbf{4 0} \pm \mathbf{1 4}$ & $-38 \pm 9$ & $-28 \pm 9$ & $-33 \pm 9$ & $-38 \pm 11$ & $-43 \pm 11$ & $-27 \pm 16$ & $-\mathbf{3 0} \pm \mathbf{1 3}$ & $-\mathbf{4 0} \pm \mathbf{1 3}$ \\
\hline NUSHAGAK & $+32 \pm 21$ & $-9 \pm 9$ & $-44 \pm 16$ & $-28 \pm 14$ & $+48 \pm 16$ & $-12 \pm 12$ & $-49 \pm 14$ & $-19 \pm 19$ & $+55 \pm 25$ & $-34 \pm 24$ & $-59 \pm 12$ & $-13 \pm 12$ \\
\hline BIOBIO* & $+8 \pm 12$ & $-12 \pm 9$ & $-44 \pm 14$ & $-61 \pm 18$ & $+12 \pm 8$ & $-33 \pm 13$ & $-66 \pm 12$ & $-78 \pm 10$ & $-25 \pm 21$ & $-75 \pm 11$ & $-89 \pm 5$ & $-89 \pm 4$ \\
\hline IRRAWADDY & $+4 \pm 5$ & $-2 \pm 5$ & $-22 \pm 7$ & $-30 \pm 9$ & $+14 \pm 7$ & $-5 \pm 5$ & $-29 \pm 9$ & $-\mathbf{3 3} \pm 9$ & $+12 \pm 13$ & $-\mathbf{2 0} \pm \mathbf{1 0}$ & $-\mathbf{3 9} \pm \mathbf{1 0}$ & $\mathbf{- 3 4} \pm \mathbf{1 0}$ \\
\hline NEGRO* & $+2 \pm 9$ & $-22 \pm 9$ & $-46 \pm 14$ & $-56 \pm 16$ & $+4 \pm 9$ & $-38 \pm 11$ & $-60 \pm 11$ & $-65 \pm 10$ & $-25 \pm 16$ & $-69 \pm 13$ & $-\mathbf{7 8} \pm \mathbf{1 0}$ & $-75 \pm 11$ \\
\hline MAJES* & $-8 \pm 15$ & $-10 \pm 20$ & $-12 \pm 17$ & $-15 \pm 14$ & $-6 \pm 22$ & $+3 \pm 16$ & $+1 \pm 11$ & $-10 \pm 15$ & $-8 \pm 41$ & $+0 \pm 49$ & $+0 \pm 50$ & $-15 \pm 42$ \\
\hline CLUTHA* & $+9 \pm 8$ & $+4 \pm 5$ & $-\mathbf{9} \pm \mathbf{7}$ & $-15 \pm 7$ & $+13 \pm 4$ & $+1 \pm 7$ & $-19 \pm 7$ & $-24 \pm 8$ & $+6 \pm 16$ & $-22 \pm 23$ & $-43 \pm 9$ & $-45 \pm 8$ \\
\hline DAULE/VINCES* & $-33 \pm 11$ & $-24 \pm 12$ & $-18 \pm 9$ & $-24 \pm 9$ & $-32 \pm 7$ & $-20 \pm 7$ & $-12 \pm 8$ & $-17 \pm 9$ & $-23 \pm 10$ & $-15 \pm 12$ & $-8 \pm 18$ & $-15 \pm 14$ \\
\hline KALIXAELVEN & $+25 \pm 11$ & $-7 \pm 12$ & $-56 \pm 21$ & $-49 \pm 16$ & $+48 \pm 18$ & $-16 \pm 14$ & $-62 \pm 11$ & $-38 \pm 20$ & $+64 \pm 38$ & $-37 \pm 21$ & $-70 \pm 8$ & $-26 \pm 23$ \\
\hline MAGDALENA & $-18 \pm 13$ & $-26 \pm 18$ & $-31 \pm 14$ & $-31 \pm 12$ & $-12 \pm 13$ & $-18 \pm 22$ & $-30 \pm 10$ & $-34 \pm 8$ & $-1 \pm 22$ & $-16 \pm 17$ & $-30 \pm 12$ & $-38 \pm 7$ \\
\hline DRAMSELV & $+24 \pm 11$ & $-10 \pm 13$ & $-56 \pm 20$ & $-\mathbf{5 7} \pm \mathbf{1 7}$ & $+\mathbf{3 7} \pm \mathbf{1 5}$ & $-17 \pm 14$ & $-59 \pm 14$ & $-54 \pm 11$ & $+47 \pm 23$ & $-\mathbf{3 7} \pm \mathbf{2 5}$ & $-70 \pm 12$ & $-52 \pm 9$ \\
\hline COLVILLE & $+44 \pm 12$ & $-36 \pm 4$ & $-42 \pm 10$ & $-36 \pm 12$ & $+60 \pm 7$ & $-41 \pm 9$ & $-43 \pm 12$ & $-7 \pm 19$ & $+77 \pm 23$ & $-49 \pm 19$ & $-41 \pm 14$ & $+82 \pm 16$ \\
\hline
\end{tabular}


Supplementary Table 5. Projected glacier runoff changes relative to basin runoff $(\%), R=\Delta Q_{\mathrm{g}}^{\prime} / Q_{\mathrm{basin}}$, including uncertainties. Monthly glacier runoff changes, $\Delta Q_{\mathrm{g}}^{\prime}$, refer to the periods 2000 to 2090, and are computed from 20-year averages centered around these years. Glacier runoff is defined as runoff from the initially glacierized area and has been shifted in time to account for water transit times to the drainage basin's mouth (see Methods). $Q_{\mathrm{g}}^{\prime} / Q_{\text {basin }}$ is shown for the months July to October (January to April for southern hemisphere, marked with *). Results refer to multi-GCM means and are given for three emission scenarios (RCP2.6, RCP4.5, RCP8.5). Uncertainties account for the combined effect of uncertainties in the (1) climate projections, (2) initial ice thickness data, (3) melt model parameterization, (4) estimated water transit time $t_{\mathrm{w}}$ to the basin's mouth, and (5) overall basin runoff (see Methods). Numbers in bold indicate cases with $|R|$ exceeding $5 \%$. Basins are ordered according to decreasing glacier area. Note that for the Santa basin (inner tropics) values of $R(-11$ to $-55 \%)$ are found between July and October.

\begin{tabular}{|c|c|c|c|c|c|c|c|c|c|c|c|c|}
\hline \multirow[t]{2}{*}{ Basin } & \multicolumn{4}{|c|}{ RCP2.6 } & \multicolumn{4}{|c|}{ RCP4.5 } & \multicolumn{4}{|c|}{ RCP8.5 } \\
\hline & $R_{\mathrm{Jul}}$ & $R_{\text {Aug }}$ & ${ }_{\%)} R_{\mathrm{Sep}}$ & $R_{\text {Oct }}$ & $R_{\mathrm{Jul}}$ & $R_{\text {Aug }}$ & $R_{\text {Sep }}$ & $R_{\text {Oct }}$ & $R_{\mathrm{Jul}}$ & $R_{\text {Aug }}$ & $R_{\text {Sep }}$ & $R_{\text {Oct }}$ \\
\hline INDUS & $+10 \pm 6$ & $+0 \pm 4$ & $-17 \pm 10$ & $-43 \pm 36$ & $+23 \pm 10$ & $+4 \pm 6$ & $-16 \pm 11$ & $\mathbf{- 3 7} \pm \mathbf{3 8}$ & $\mathbf{+ 3 8} \pm \mathbf{1 3}$ & $+3 \pm 10$ & $-23 \pm 20$ & $-22 \pm 56$ \\
\hline TARIM & $+16 \pm 7$ & $+7 \pm 9$ & $-43 \pm 40$ & $-54 \pm 45$ & $+\mathbf{3 6} \pm 10$ & $+\mathbf{2 0} \pm \mathbf{1 7}$ & $-33 \pm 43$ & $-37 \pm 40$ & $+52 \pm 16$ & $+10 \pm 31$ & $-57 \pm 59$ & $-22 \pm 60$ \\
\hline BRAHMAPUTRA & $+1 \pm 0$ & $-1 \pm 0$ & $-3 \pm 2$ & $-3 \pm 2$ & $+2 \pm 0$ & $-1 \pm 1$ & $-4 \pm 1$ & $-3 \pm 1$ & $+2 \pm 1$ & $-3 \pm 2$ & $-5 \pm 3$ & $-3 \pm 3$ \\
\hline ARAL SEA & $+14 \pm 6$ & $+7 \pm 8$ & $-32 \pm 24$ & $-52 \pm 34$ & $+29 \pm 8$ & $+16 \pm 15$ & $-38 \pm 28$ & $-\mathbf{5 4} \pm \mathbf{3 6}$ & $+43 \pm 13$ & $+5 \pm 26$ & $-64 \pm 39$ & $-60 \pm 46$ \\
\hline COPPER & $+\mathbf{5} \pm \mathbf{7}$ & $+0 \pm 7$ & $+5 \pm 9$ & $\mathbf{+ 1 1} \pm \mathbf{1 7}$ & $+\mathbf{1 0} \pm 9$ & $+6 \pm 8$ & $+15 \pm 14$ & $+28 \pm 28$ & $+19 \pm 15$ & $+18 \pm 14$ & $\mathbf{+ 3 5} \pm \mathbf{2 0}$ & $+60 \pm 54$ \\
\hline GANGES & $+2 \pm 1$ & $-1 \pm 1$ & $-3 \pm 2$ & $-2 \pm 2$ & $+4 \pm 2$ & $-0 \pm 1$ & $-3 \pm 1$ & $-2 \pm 1$ & $+6 \pm 7$ & $-1 \pm 1$ & $-3 \pm 3$ & $-1 \pm 2$ \\
\hline YUKON & $+3 \pm 1$ & $+1 \pm 1$ & $-1 \pm 2$ & $+1 \pm 2$ & $+4 \pm 1$ & $+3 \pm 2$ & $+2 \pm 3$ & $+3 \pm 3$ & $+8 \pm 2$ & $+8 \pm 7$ & $+8 \pm 9$ & $+\mathbf{1 0} \pm 5$ \\
\hline ALSEK & $+1 \pm 8$ & $\mathbf{- 8} \pm \mathbf{1 0}$ & $+3 \pm 8$ & $\mathbf{+ 2 3} \pm \mathbf{2 1}$ & $+4 \pm 11$ & $-5 \pm 13$ & $+\mathbf{1 2} \pm 11$ & $+45 \pm 32$ & $+\mathbf{8} \pm \mathbf{2 2}$ & $+1 \pm 30$ & $\mathbf{+ 2 7} \pm \mathbf{2 3}$ & $+86 \pm 39$ \\
\hline SUSITNA & $+1 \pm 4$ & $-0 \pm 14$ & $+2 \pm 15$ & $+2 \pm 16$ & $+4 \pm 5$ & $+2 \pm 16$ & $+6 \pm 22$ & $+5 \pm 31$ & $\mathbf{+ 9} \pm \mathbf{1 3}$ & $\mathbf{+ 9} \pm \mathbf{2 7}$ & $\mathbf{+ 1 7} \pm \mathbf{2 8}$ & $+12 \pm 44$ \\
\hline BALKHASH & $+\mathbf{1 2} \pm 5$ & $-3 \pm 7$ & $\mathbf{- 3 0} \pm \mathbf{1 3}$ & $-8 \pm \mathbf{4}$ & $+25 \pm 6$ & $-6 \pm 14$ & $-35 \pm 15$ & $-7 \pm 5$ & $+\mathbf{2 7} \pm \mathbf{1 0}$ & $-30 \pm 24$ & $-46 \pm 14$ & $-5 \pm 7$ \\
\hline STIKINE & $-3 \pm 1$ & $-15 \pm 5$ & $-11 \pm 5$ & $+0 \pm 2$ & $-4 \pm 2$ & $-\mathbf{- 1 8} \pm 5$ & $-13 \pm 4$ & $+3 \pm 3$ & $-10 \pm 5$ & $-23 \pm 8$ & $-14 \pm 6$ & $+\mathbf{+ 1 1} \pm 6$ \\
\hline SANTA CRUZ* & $+0 \pm 5$ & $+2 \pm 3$ & $+2 \pm 2$ & $-0 \pm 2$ & $+9 \pm 6$ & $+7 \pm 4$ & $+8 \pm \mathbf{4}$ & $+7 \pm 3$ & $+21 \pm 7$ & $+15 \pm 7$ & $+15 \pm 6$ & $+\mathbf{1 5} \pm 5$ \\
\hline FRASER & $-0 \pm 0$ & $\mathbf{- 9} \pm \mathbf{3}$ & $-18 \pm 5$ & $-\mathbf{1 0} \pm \mathbf{3}$ & $-0 \pm 1$ & $-11 \pm 2$ & $-21 \pm 3$ & $-10 \pm 2$ & $-2 \pm 1$ & $-16 \pm 3$ & $-25 \pm 3$ & $-10 \pm 2$ \\
\hline BAKER ${ }^{*}$ & $-5 \pm 2$ & $-12 \pm 4$ & $-15 \pm 5$ & $-\mathbf{8} \pm \mathbf{3}$ & $\mathbf{- 8} \pm \mathbf{3}$ & $-16 \pm 4$ & $-17 \pm 4$ & $-8 \pm \mathbf{2}$ & $-19 \pm 5$ & $-25 \pm 5$ & $-23 \pm 5$ & $-8 \pm 2$ \\
\hline YANGTZE & $+0 \pm 0$ & $-0 \pm 0$ & $-1 \pm 0$ & $-0 \pm 0$ & $+0 \pm 0$ & $-0 \pm 0$ & $-1 \pm 0$ & $-0 \pm 0$ & $+0 \pm 0$ & $-0 \pm 0$ & $-1 \pm 0$ & $-0 \pm 0$ \\
\hline SALWEEN & $+0 \pm 0$ & $-2 \pm 0$ & $-2 \pm 1$ & $-1 \pm 0$ & $+1 \pm 0$ & $-2 \pm 0$ & $-2 \pm 0$ & $-1 \pm 0$ & $-1 \pm 1$ & $-3 \pm 1$ & $-2 \pm 1$ & $-0 \pm 0$ \\
\hline COLUMBIA & $+0 \pm 0$ & $-5 \pm 1$ & $-11 \pm 3$ & $-5 \pm 1$ & $+0 \pm 1$ & $-6 \pm 2$ & $-12 \pm 1$ & $-5 \pm 1$ & $-1 \pm 1$ & $-9 \pm 2$ & $-13 \pm 1$ & $-5 \pm 1$ \\
\hline ISSYK-KUL & $+3 \pm 1$ & $-1 \pm 1$ & $-17 \pm 8$ & $-12 \pm 5$ & $+7 \pm 1$ & $-2 \pm 3$ & $-21 \pm 9$ & $-12 \pm 5$ & $+7 \pm 2$ & $-9 \pm 6$ & $-29 \pm 9$ & $-12 \pm 7$ \\
\hline AMAZON* & $-0 \pm 0$ & $-0 \pm 0$ & $-0 \pm 0$ & $-0 \pm 0$ & $-0 \pm 0$ & $-0 \pm 0$ & $-0 \pm 0$ & $-0 \pm 0$ & $-0 \pm 0$ & $-0 \pm 0$ & $-0 \pm 0$ & $-0 \pm 0$ \\
\hline COLORADO* & $-0 \pm 2$ & $-19 \pm 8$ & $-24 \pm 14$ & $-16 \pm 7$ & $+1 \pm 4$ & $-26 \pm 10$ & $-32 \pm 15$ & $-17 \pm 10$ & $-3 \pm 6$ & $-36 \pm 12$ & $-37 \pm 14$ & $-18 \pm 9$ \\
\hline TAKU & $-5 \pm 3$ & $-20 \pm 8$ & $-\mathbf{- 1 0} \pm 5$ & $+2 \pm 7$ & $-4 \pm 2$ & $-19 \pm 5$ & $-6 \pm 12$ & $+\mathbf{1 1} \pm \mathbf{1 5}$ & $-4 \pm 11$ & $-14 \pm 11$ & $+5 \pm 27$ & $\mathbf{+ 3 6} \pm \mathbf{3 7}$ \\
\hline MACKENZIE & $+0 \pm 0$ & $-1 \pm 0$ & $-3 \pm 0$ & $-3 \pm 1$ & $+1 \pm 0$ & $-1 \pm 0$ & $-3 \pm 0$ & $-3 \pm 1$ & $+1 \pm 0$ & $-1 \pm 0$ & $-3 \pm 0$ & $-3 \pm 1$ \\
\hline NASS & $-2 \pm 2$ & $-12 \pm 9$ & $\mathbf{- 8} \pm \mathbf{1 0}$ & $+4 \pm 8$ & $-3 \pm 5$ & $-15 \pm 9$ & $\mathbf{- 9} \pm \mathbf{1 3}$ & $+7 \pm 14$ & $\mathbf{- 8} \pm \mathbf{1 0}$ & $-19 \pm 15$ & $-11 \pm 22$ & $+15 \pm 30$ \\
\hline THJORSA & $-11 \pm 9$ & $\mathbf{- 2 1} \pm \mathbf{1 1}$ & $-\mathbf{1 0} \pm 10$ & $-2 \pm 6$ & $-9 \pm 9$ & $-16 \pm 9$ & $-4 \pm 11$ & $+5 \pm 7$ & $-2 \pm 12$ & $-8 \pm 15$ & $+6 \pm 14$ & $+18 \pm 11$ \\
\hline JOEKULSA A F. & $+3 \pm 10$ & $-2 \pm 11$ & $+8 \pm 17$ & $\mathbf{+ 8} \pm \mathbf{1 7}$ & $+\mathbf{1 2} \pm \mathbf{1 7}$ & $+\mathbf{9} \pm \mathbf{1 3}$ & $+23 \pm 26$ & $+24 \pm 25$ & $+29 \pm 24$ & $+23 \pm 27$ & $\mathbf{+ 4 3} \pm 34$ & $\mathbf{+ 5 0} \pm \mathbf{3 7}$ \\
\hline KUSKOKWIM & $+0 \pm 2$ & $-3 \pm 2$ & $-3 \pm 3$ & $-0 \pm 3$ & $+1 \pm 2$ & $-3 \pm 3$ & $-2 \pm 4$ & $+1 \pm 5$ & $+1 \pm 4$ & $-4 \pm 6$ & $-1 \pm 6$ & $+2 \pm 11$ \\
\hline RHONE & $-2 \pm 1$ & $-11 \pm 3$ & $-8 \pm \mathbf{2}$ & $-2 \pm 1$ & $-2 \pm 1$ & $-\mathbf{1 3} \pm \mathbf{3}$ & $-9 \pm 2$ & $-2 \pm 0$ & $-6 \pm 2$ & $-18 \pm 3$ & $-11 \pm 2$ & $-2 \pm 0$ \\
\hline SKEENA & $-2 \pm 1$ & $-18 \pm 6$ & $-18 \pm 5$ & $-4 \pm 1$ & $-4 \pm 1$ & $-21 \pm 4$ & $-20 \pm 2$ & $-2 \pm 2$ & $-\mathbf{8} \pm \mathbf{3}$ & $-25 \pm 4$ & $-21 \pm 2$ & $+1 \pm 2$ \\
\hline OB & $+0 \pm 0$ & $+0 \pm 0$ & $-0 \pm 0$ & $-1 \pm 0$ & $+0 \pm 0$ & $+0 \pm 0$ & $-0 \pm 0$ & $-1 \pm 0$ & $+0 \pm 0$ & $+0 \pm 0$ & $-0 \pm 0$ & $-1 \pm 0$ \\
\hline OELFUSA & $\mathbf{- 9} \pm \mathbf{5}$ & $-18 \pm 8$ & $-9 \pm 5$ & $-1 \pm 2$ & $-12 \pm 6$ & $-18 \pm 8$ & $-8 \pm 5$ & $+2 \pm 2$ & $-\mathbf{- 1 4} \pm 8$ & $-18 \pm 10$ & $-7 \pm 7$ & $+6 \pm 3$ \\
\hline MEKONG & $+0 \pm 0$ & $-0 \pm 0$ & $-0 \pm 0$ & $-0 \pm 0$ & $+0 \pm 0$ & $-0 \pm 0$ & $-0 \pm 0$ & $-0 \pm 0$ & $+0 \pm 0$ & $-0 \pm 0$ & $-0 \pm 0$ & $-0 \pm 0$ \\
\hline DANUBE & $+0 \pm 0$ & $-1 \pm 0$ & $-2 \pm 0$ & $-1 \pm 0$ & $+0 \pm 0$ & $-1 \pm 0$ & $-2 \pm 0$ & $-1 \pm 0$ & $+0 \pm 0$ & $-2 \pm 0$ & $-3 \pm 0$ & $-1 \pm 0$ \\
\hline NELSON & $+0 \pm 0$ & $-1 \pm 0$ & $-2 \pm 0$ & $-2 \pm 0$ & $+1 \pm 0$ & $-1 \pm 0$ & $-2 \pm 0$ & $-2 \pm 0$ & $+1 \pm 0$ & $-1 \pm 0$ & $-3 \pm 0$ & $-2 \pm 0$ \\
\hline $\mathrm{PO}$ & $-1 \pm 0$ & $-6 \pm 1$ & $-4 \pm 1$ & $-1 \pm 0$ & $-1 \pm 0$ & $-7 \pm 1$ & $-4 \pm 0$ & $-1 \pm 0$ & $-3 \pm 1$ & $-\mathbf{9} \pm \mathbf{1}$ & $-5 \pm 0$ & $-1 \pm 0$ \\
\hline КАМСНАТКА & $-0 \pm 0$ & $-2 \pm 0$ & $-1 \pm 0$ & $-0 \pm 0$ & $-0 \pm 0$ & $-2 \pm 1$ & $-1 \pm 0$ & $-0 \pm 0$ & $-1 \pm 0$ & $-3 \pm 1$ & $-1 \pm 1$ & $+0 \pm 0$ \\
\hline RHINE & $-0 \pm 0$ & $-2 \pm 0$ & $-2 \pm 0$ & $-1 \pm 0$ & $-0 \pm 0$ & $-2 \pm 0$ & $-2 \pm 0$ & $-1 \pm 0$ & $-1 \pm 0$ & $-3 \pm 0$ & $-3 \pm 0$ & $-1 \pm 0$ \\
\hline GLOMA & $-1 \pm 0$ & $-5 \pm 1$ & $-4 \pm 1$ & $-1 \pm 0$ & $-1 \pm 0$ & $-\mathbf{5} \pm \mathbf{1}$ & $-3 \pm 0$ & $-1 \pm 0$ & $-2 \pm 1$ & $-6 \pm 1$ & $-3 \pm 0$ & $-0 \pm 0$ \\
\hline HUANG HE & $+1 \pm 0$ & $-0 \pm 0$ & $-1 \pm 0$ & $-0 \pm 0$ & $+1 \pm 0$ & $-0 \pm 0$ & $-1 \pm 0$ & $-0 \pm 0$ & $+1 \pm 0$ & $-1 \pm 0$ & $-1 \pm 0$ & $-0 \pm 0$ \\
\hline INDIGIRKA & $-0 \pm 0$ & $-1 \pm 0$ & $-1 \pm 0$ & $-1 \pm 0$ & $+0 \pm 0$ & $-1 \pm 0$ & $-1 \pm 0$ & $-1 \pm 0$ & $-0 \pm 0$ & $-1 \pm 0$ & $-1 \pm 0$ & $-0 \pm 0$ \\
\hline LULE & $+0 \pm 0$ & $-4 \pm 1$ & $-3 \pm 1$ & $-1 \pm 0$ & $-0 \pm 1$ & $-5 \pm 1$ & $-3 \pm 1$ & $-0 \pm 0$ & $-2 \pm 1$ & $-7 \pm 1$ & $-3 \pm 1$ & $+1 \pm 1$ \\
\hline RAPEL* & $-10 \pm 3$ & $-35 \pm 13$ & $-44 \pm 16$ & $-14 \pm 6$ & $-14 \pm 5$ & $-48 \pm 14$ & $-52 \pm 17$ & $-16 \pm 6$ & $-24 \pm 7$ & $-62 \pm 13$ & $-60 \pm 15$ & $-17 \pm 6$ \\
\hline SANTA* & $+1 \pm 2$ & $+2 \pm 3$ & $+1 \pm 1$ & $-3 \pm 3$ & $+2 \pm 4$ & $+3 \pm 5$ & $+1 \pm 2$ & $-3 \pm 2$ & $+4 \pm 12$ & $+5 \pm 13$ & $+3 \pm 7$ & $-2 \pm 3$ \\
\hline SKAGIT & $-0 \pm 0$ & $-7 \pm 2$ & $-\mathbf{1 1} \pm \mathbf{3}$ & $-3 \pm 1$ & $-0 \pm 0$ & $\mathbf{- 9} \pm \mathbf{2}$ & $-13 \pm 1$ & $-3 \pm 0$ & $-3 \pm 2$ & $-13 \pm 2$ & $-16 \pm 2$ & $-2 \pm 0$ \\
\hline KUBAN & $+1 \pm 0$ & $-4 \pm 2$ & $-\mathbf{8} \pm \mathbf{3}$ & $-5 \pm 1$ & $+0 \pm 0$ & $-6 \pm 1$ & $-\mathbf{9} \pm \mathbf{1}$ & $-5 \pm 0$ & $-2 \pm 1$ & $-9 \pm 1$ & $-11 \pm 2$ & $-5 \pm 1$ \\
\hline TITICACA* & $-0 \pm 0$ & $-0 \pm 0$ & $-1 \pm 0$ & $-1 \pm 0$ & $-0 \pm 0$ & $-0 \pm 0$ & $-1 \pm 0$ & $-1 \pm 0$ & $-1 \pm 0$ & $-0 \pm 0$ & $-1 \pm 0$ & $-1 \pm 0$ \\
\hline NUSHAGAK & $-0 \pm 0$ & $-1 \pm 0$ & $-1 \pm 0$ & $-0 \pm 0$ & $-0 \pm 0$ & $-1 \pm 0$ & $-1 \pm 0$ & $-0 \pm 0$ & $-1 \pm 0$ & $-2 \pm 1$ & $-1 \pm 0$ & $-0 \pm 0$ \\
\hline BIOBIO* & $-1 \pm 0$ & $-3 \pm 1$ & $-4 \pm 1$ & $-1 \pm 0$ & $-2 \pm 0$ & $-5 \pm 1$ & $-6 \pm 0$ & $-2 \pm 0$ & $-4 \pm 0$ & $-7 \pm 1$ & $-7 \pm 0$ & $-2 \pm 0$ \\
\hline IRRAWADDY & $-0 \pm 0$ & $-0 \pm 0$ & $-0 \pm 0$ & $-0 \pm 0$ & $-0 \pm 0$ & $-0 \pm 0$ & $-0 \pm 0$ & $-0 \pm 0$ & $-0 \pm 0$ & $-0 \pm 0$ & $-0 \pm 0$ & $-0 \pm 0$ \\
\hline NEGRO* & $-1 \pm 0$ & $-2 \pm 0$ & $-2 \pm 0$ & $-1 \pm 0$ & $-1 \pm 0$ & $-2 \pm 0$ & $-2 \pm 0$ & $-1 \pm 0$ & $-3 \pm 0$ & $-3 \pm 0$ & $-3 \pm 0$ & $-1 \pm 0$ \\
\hline MAJES* & $-0 \pm 0$ & $-0 \pm 0$ & $-0 \pm 0$ & $-0 \pm 0$ & $-0 \pm 0$ & $-0 \pm 0$ & $-0 \pm 0$ & $-0 \pm 0$ & $-0 \pm 0$ & $-0 \pm 0$ & $-0 \pm 0$ & $-0 \pm 0$ \\
\hline CLUTHA* & $+0 \pm 0$ & $-0 \pm 0$ & $-1 \pm 0$ & $-0 \pm 0$ & $+0 \pm 0$ & $-1 \pm 0$ & $-1 \pm 0$ & $-0 \pm 0$ & $-1 \pm 0$ & $-1 \pm 0$ & $-1 \pm 0$ & $-0 \pm 0$ \\
\hline DAULE/VINCES* & $-0 \pm 0$ & $-0 \pm 0$ & $-0 \pm 0$ & $-0 \pm 0$ & $-0 \pm 0$ & $-0 \pm 0$ & $-0 \pm 0$ & $-0 \pm 0$ & $-0 \pm 0$ & $-0 \pm 0$ & $-0 \pm 0$ & $-0 \pm 0$ \\
\hline KALIXAELVEN & $-0 \pm 0$ & $-1 \pm 0$ & $-1 \pm 0$ & $-0 \pm 0$ & $-0 \pm 0$ & $-2 \pm 0$ & $-1 \pm 0$ & $-0 \pm 0$ & $-1 \pm 0$ & $-2 \pm 0$ & $-1 \pm 0$ & $+0 \pm 0$ \\
\hline MAGDALENA & $-0 \pm 0$ & $-0 \pm 0$ & $-0 \pm 0$ & $-0 \pm 0$ & $-0 \pm 0$ & $-0 \pm 0$ & $-0 \pm 0$ & $-0 \pm 0$ & $-0 \pm 0$ & $-0 \pm 0$ & $-0 \pm 0$ & $-0 \pm 0$ \\
\hline DRAMSELV & $-0 \pm 0$ & $-2 \pm 0$ & $-1 \pm 0$ & $-0 \pm 0$ & $-0 \pm 0$ & $-2 \pm 0$ & $-1 \pm 0$ & $-0 \pm 0$ & $-1 \pm 0$ & $-2 \pm 0$ & $-1 \pm 0$ & $+0 \pm 0$ \\
\hline COLVILLE & $-0 \pm 1$ & $-1 \pm 5$ & $-0 \pm 7$ & $-0 \pm 10$ & $-0 \pm 1$ & $-1 \pm 7$ & $-0 \pm 10$ & $-0 \pm 7$ & $-0 \pm 6$ & $-1 \pm 12$ & $-0 \pm 13$ & $+0 \pm 5$ \\
\hline
\end{tabular}


Supplementary Table 6. Observed long-term average monthly runoff ${ }^{5,6}$ for June to September for the 56 investigated basins. For each basin the name of the gauging station, the country (two-letter code) and the time period for which data were available is listed. For basins lacking a station name, direct measurements were not available (13\% of the basins), and we used the global-scale data set by Fekete et al. ${ }^{5}$, which is based on grid-based macroscopic hydrological modelling. Note that for drainage basins in the Southern hemisphere (marked with *, 21\% of the basins) runoff refers to the months December, January, February and March. Basins are ordered according to decreasing glacier area.

\begin{tabular}{|c|c|c|c|c|c|c|c|}
\hline Basin & Station & Nat. & Period & $\begin{array}{r}Q_{\text {June }} \\
\left(\mathrm{m}^{3} \mathrm{~s}^{-1}\right)\end{array}$ & $\begin{array}{r}Q_{\text {July }} \\
\left(\mathrm{m}^{3} \mathrm{~s}^{-1}\right)\end{array}$ & $\begin{array}{r}Q_{\text {Aug }} \\
\left(\mathrm{m}^{3} \mathrm{~s}^{-1}\right)\end{array}$ & $\begin{array}{r}Q_{\text {Sept }} \\
\left(\mathrm{m}^{3} \mathrm{~s}^{-1}\right)\end{array}$ \\
\hline INDUS & KOTRI & PK & 1936-1979 & 3,623 & 6,552 & 10,724 & 6,073 \\
\hline TARIM & & & 1986-1995 & 6,154 & 4,102 & 3,184 & 1,732 \\
\hline BRAHMAPUTRA & BAHADURABAD & BD & 1969-1992 & 32,398 & 49,111 & 45,017 & 43,805 \\
\hline ARAL SEA & CHATLY & $\mathrm{UZ}$ & $1936-1973$ & 2,978 & 3,548 & 2,958 & 1,911 \\
\hline COPPER & CORDOVA & US & $1988-2014$ & 4,028 & 5,378 & 4,824 & 3,082 \\
\hline GANGES & FARAKKA & IN & $1949-1973$ & 4,314 & 20,793 & 43,030 & 36,899 \\
\hline YUKON & PILOT & US & 1975-2014 & 16,161 & 12,609 & 11,133 & 10,146 \\
\hline ALSEK & YAKUTAT & US & 1991-2012 & 1,995 & 2,528 & 2,241 & 1,357 \\
\hline SUSITNA & SUSITNA & US & 1974-2014 & 3,378 & 3,653 & 3,164 & 2,170 \\
\hline BALKHASH & USH-TOBE & $\mathrm{KZ}$ & 1965-1985 & 1,553 & 1,246 & 742 & 842 \\
\hline STIKINE & WRANGELL & US & 1976-2014 & 3,875 & 3,766 & 3,000 & 2,327 \\
\hline SANTA CRUZ* & CHARLES FUHR & $\mathrm{AR}$ & 1955-1994 & 599 & 839 & 1,099 & 1,291 \\
\hline FRASER & HOPE & CA & $1912-2012$ & 7,000 & 5,544 & 3,516 & 2,342 \\
\hline BAKER* $^{*}$ & COLONIA & $\mathrm{CL}$ & 1963-1984 & 1,029 & 1,181 & 1,184 & 1,077 \\
\hline YANGTZE & DATONG & $\mathrm{CN}$ & $1922-1988$ & 40,170 & 48,818 & 44,315 & 41,806 \\
\hline SALWEEN & & & 1986-1995 & 1,706 & 5,355 & 8,252 & 7,645 \\
\hline COLUMBIA & QUINCY & US & $1968-2014$ & 9,521 & 6,371 & 4,566 & 3,573 \\
\hline ISSYK-KUL & UST.DJUMGOL & KG & $1933-1980$ & 2,677 & 2,180 & 1,246 & 767 \\
\hline AMAZON* & OBIDOS & $\mathrm{BR}$ & 1928-1996 & 122,148 & 138,439 & 156,123 & 177,162 \\
\hline COLORADO* & & & 1986-1995 & 1,589 & 778 & 518 & 367 \\
\hline TAKU & JUNEAU & US & $1987-2014$ & 999 & 909 & 735 & 546 \\
\hline MACKENZIE & RED RIVER & $\mathrm{CA}$ & $1972-2013$ & 20,774 & 17,245 & 13,772 & 11,558 \\
\hline NASS & SHUMAL CREEK & CA & 1929-2012 & 2,079 & 1,665 & 1,175 & 887 \\
\hline THJORSA & THJORSARTUN & IS & $1947-2014$ & 498 & 444 & 442 & 353 \\
\hline JOEKULSA A F. & FERJUBAKKI & IS & 1940-1991 & 230 & 323 & 352 & 238 \\
\hline KUSKOKWIM & CROOKED CREEK & US & 1951-2014 & 2,253 & 1,896 & 2,096 & 1,907 \\
\hline RHONE & BEAUCAIRE & FR & 1920-1999 & 1,818 & 1,384 & 1,097 & 1,155 \\
\hline SKEENA & USK & $\mathrm{CA}$ & $1928-2011$ & 2,841 & 1,734 & 951 & 767 \\
\hline $\mathrm{OB}$ & SALEKHARD & RU & 1930-1994 & 32,994 & 29,759 & 21,964 & 13,753 \\
\hline OELFUSA & SELFOSS & IS & $1950-2014$ & 410 & 373 & 369 & 365 \\
\hline MEKONG & PHNOM PENH & $\mathrm{KH}$ & $1960-1973$ & 9,509 & 21,657 & 33,391 & 37,676 \\
\hline DANUBE & CEATAL IZMAIL & RO & $1931-2010$ & 8,158 & 6,897 & 5,399 & 4,679 \\
\hline NELSON & SPRUCE & $\mathrm{CA}$ & $1987-2011$ & 3,478 & 3,593 & 3,649 & 3,507 \\
\hline $\mathrm{PO}$ & PONTELAGOSCURO & IT & $1918-1998$ & 1,855 & 1,205 & 949 & 1,339 \\
\hline КАМСНАТКА & SCHEKI & RU & $1937-1987$ & 1,804 & 2,139 & 1,265 & 938 \\
\hline RHINE & LOBITH & NL & $1901-2013$ & 2,240 & 2,114 & 1,841 & 1,689 \\
\hline GLOMA & LANGNES & $\mathrm{NO}$ & 1988-2014 & 1,345 & 1,026 & 828 & 709 \\
\hline HUANG HE & SANMENXIA & $\mathrm{CN}$ & $1953-1988$ & 834 & 1,773 & 2,388 & 2,412 \\
\hline INDIGIRKA & VORONTSOVO & RU & 1950-1996 & 5,705 & 5,356 & 4,235 & 2,604 \\
\hline LULE & BODENS & SE & $1900-2012$ & 828 & 891 & 759 & 597 \\
\hline RAPEL* & CORNECHE & $\mathrm{CL}$ & 1966-1979 & 178 & 129 & 62 & 51 \\
\hline SANTA* & & & 1986-1995 & 84 & 158 & 221 & 275 \\
\hline SKAGIT & MOUNT VERNON & US & $1940-2014$ & 694 & 574 & 330 & 265 \\
\hline KUBAN & TIKHOVSKY & RU & $1936-2002$ & 618 & 534 & 385 & 276 \\
\hline TITICACA* & & & 1986-1995 & 1,220 & 1,706 & 1,734 & 1,579 \\
\hline NUSHAGAK & EKWOK & US & 1977-1993 & 1,214 & 949 & 813 & 912 \\
\hline BIOBIO* $^{*}$ & DESEMBOCADURA & $\mathrm{CL}$ & 1963-1992 & 745 & 377 & 262 & 248 \\
\hline IRRAWADDY & & & 1986-1995 & 17,302 & 34,147 & 34,324 & 29,044 \\
\hline NEGRO* & PALMAR & UY & 1910-1979 & 466 & 312 & 380 & 416 \\
\hline MAJES* & & & 1986-1995 & 228 & 371 & 470 & 370 \\
\hline CLUTHA* & BALCLUTHA & $\mathrm{NZ}$ & 1954-2009 & 683 & 627 & 517 & 497 \\
\hline DAULE/VINCES* & LACAPILLA & $\mathrm{EC}$ & 1970-2005 & 265 & 512 & 1,014 & 1,230 \\
\hline KALIXAELVEN & RAEKTFORS & SE & $1937-2013$ & 684 & 504 & 390 & 334 \\
\hline MAGDALENA & CALAMAR & $\mathrm{CO}$ & $1971-1990$ & 8,306 & 7,966 & 7,241 & 7,532 \\
\hline DRAMSELV & DOVIKFOSS & NO & 1912-2005 & 579 & 381 & 324 & 304 \\
\hline COLVILLE & UMIAT & US & 2002-2014 & 1,463 & 460 & 478 & 337 \\
\hline
\end{tabular}




\section{References}

1. Jansson, P., Hock, R. \& Schneider, T. The concept of glacier storage - a review. Journal of Hydrology 282, 116-129 (2003). DOI 10.1016/S00221694(03)00258-0.

2. Milner, A. M., Brown, L. E. \& Hannah, D. M. Hydroecological response of river systems to shrinking glaciers. Hydrological Processes 23, 62-77 (2009). DOI 10.1002/hyp.7197.

3. Moore, R. D. et al. Glacier change in western North America: influences on hydrology, geomorphic hazards and water quality. Hydrological Processes $\mathbf{2 3}$, 42-61 (2009). DOI 10.1002/hyp.7162.

4. Baraer, M. et al. Glacier recession and water resources in Peru's Cordillera Blanca. Journal of Glaciology 58, 134-150 (2012). DOI $10.3189 / 2012 \mathrm{JoG} 11 \mathrm{~J} 186$.

5. Fekete, B., Vörösmarty, C. \& Grabs, W. High-resolution fields of global runoff combining observed river discharge and simulated water balances. Global Biogeochemical Cycles 16, 15-1-15-10 (2002). DOI 10.1029/1999GB001254.

6. GRDC. Long-term mean monthly discharges and annual characteristics of GRDC Stations / online provided by the Global Runoff Data Centre of WMO. (Date of retrieval: 2016-06-17). (2015).

7. GRDC. Major River Basins of the World / Global Runoff Data Centre (2007). URL http: / / www . bafg . de / GRDC/.

8. Arendt, A. et al. Randolph Glacier Inventory - A Dataset of Global Glacier Outlines: Version 4.0. Global Land Ice Measurements from Space, Boulder Colorado, USA. Digital Media (2014).

9. Center for International Earth Science Information Network (CIESIN), C. U. \& de Agricultura Tropical (CIAT), C. I. Gridded Population of the World Version 3 (GPWv3): Population Density Grids (2005).

10. Nieuwenhuyse, E. V. Empirical model for predicting a catchment-scale metric of surface water transit time in streams. Can. J. Fish. Aquat. Sci. 62, 492-504 (2005). DOI 10.1139/f04-202.

11. Taylor, K. E., Stouffer, R. J. \& Meehl, G. A. An Overview of CMIP5 and the Experiment Design. Bulletin of the American Meteorological Society 93, 485-498 (2012). DOI 10.1175/BAMS-D-11-00094.1. 